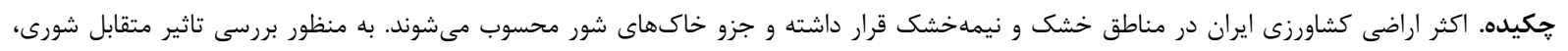

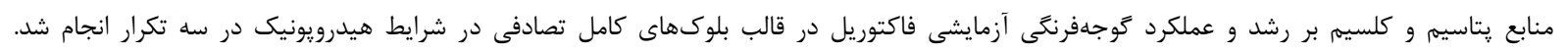

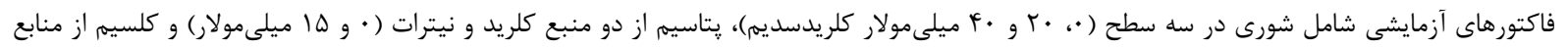

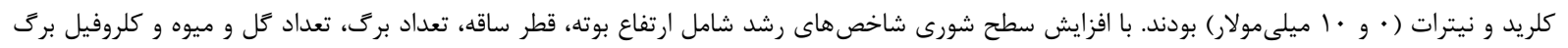

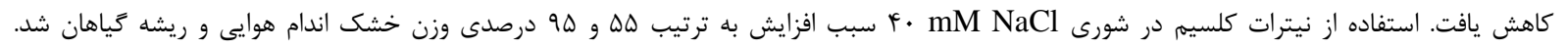

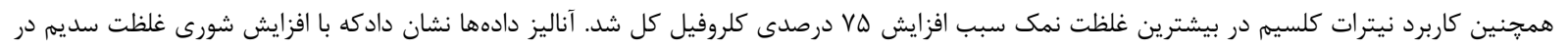

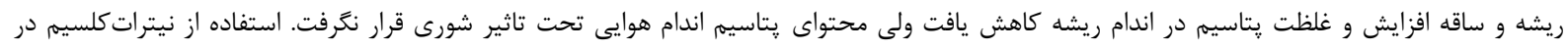

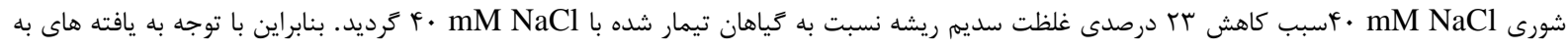

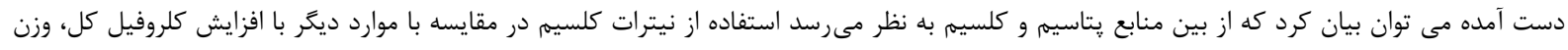

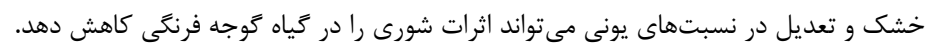$$
\text { وازههاى كليدى. سديم، رشد، كلروفيل، كلدهى، ميوه }
$$

\title{
The effects of different sources of potassium and calcium on yield and ionic balance of tomatoes under salinity stress in hydroponic cultivation
}

\section{Akbar Forghani ${ }^{1}$, Amir Hossein Forghani $^{2}$, Maryam Altafi ${ }^{1}$, Kazem Hashemi Majd ${ }^{3}$ \& Omid Sofalian ${ }^{4}$}

${ }^{1}$ Department of Soil Science, Faculty of Agriculture Science, University of Guilan, Rasht, Iran; ${ }^{2}$ Department of Biology, Faculty of Science, Payame Noor University, P.O. BOX 19395-3697 Tehran, Iran; ${ }^{3}$ Department of Soil Science, Faculty of Agriculture Science, University of Mohaghegh Ardabili, Ardabil, Iran; ${ }^{4}$ Department of Agronomy and Plant Breeding, Faculty of Agriculture Science, University of Mohaghegh Ardabili, Ardabil, Iran

Correspondent author: Akbar Forghani, Forghani@ pnu.ac.ir

\begin{abstract}
Most of agricultural lands in Iran are located in arid and semi-arid regions and are considered as saline soils. In order to investigate the interaction of salinity as well as potassium and calcium on the growth and yield of tomato plants, a factorial experiment was perfected in the form of randomized complete blocks, in hydroponic conditions, with three replicates per treatment. Experimental factors include salinity at three levels $(0,20$, and $40 \mathrm{mM} \mathrm{NaCl})$, potassium content form chloride, nitrate $(0$ and $15 \mathrm{mM})$, and calcium from chloride, and nitrate (with 0 and $10 \mathrm{mM})$. The studied growth factors, including plant height, stem diameter, number of leaves, flowers and fruits and leaf chlorophyll decreased
\end{abstract}


with increase $\mathrm{NaCl}$. Treatment plants with $\mathrm{Ca}\left(\mathrm{NO}_{3}\right)_{2}$ at $40 \mathrm{mM} \mathrm{NaCl}$, increased the shoot and root dry weight by $55 \%$ and $95 \%$, respectively. In addition, application of $\mathrm{Ca}\left(\mathrm{NO}_{3}\right)_{2}$ in the medium with maximum salinity concentration resulted in an increase of $75 \%$ in chlorophyll content. The analysis of data showed that the increase of salinity was accompanied with increase sodium content level of tomato plants. However, the root potassium was observed to decrease. On the contrast to the root, potassium content showed no change in the organs from the root upwards. Also, the use of $\mathrm{Ca}\left(\mathrm{NO}_{3}\right)_{2}$ with $40 \mathrm{mM} \mathrm{NaCl}$ reduced $\mathrm{Na}^{+}$content by $23 \%$ compared with plants treated only with $40 \mathrm{mM}$ $\mathrm{NaCl}$. According to the results, it seems that application of $\mathrm{Ca}\left(\mathrm{NO}_{3}\right)_{2}$ may improve chlorophyll content, dry weight, and modulate ion hemostasis and decreased the negative of salt stress in tomato plants.

Key words. chlorophyll, flowering, fruit, growth, sodium

زراعى نسبت به شورى حساس هستند (asanuzzaman et مقدمه

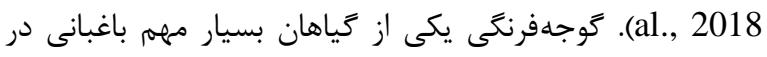

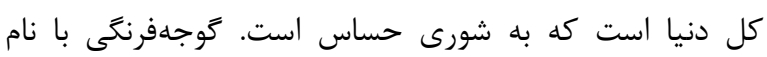
علمى Lycopersicon esculentum كياهى است علفى، تهند ساله و از خانواده بادمجان است. توليد كوجهفرنكَى در كلخانهانها يا ساير ساختارهاى حفاظتى در مناطقى كه شرايط آب و هوائى آنى دادي،

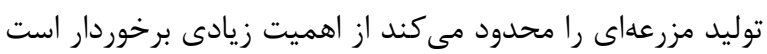

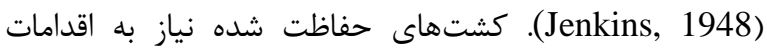

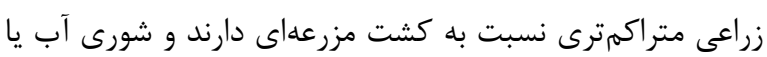

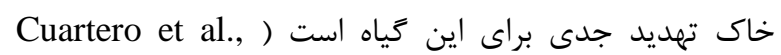

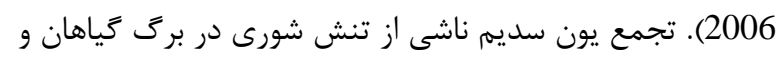

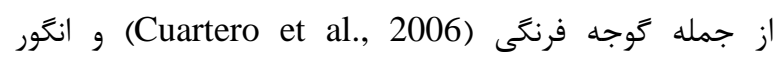

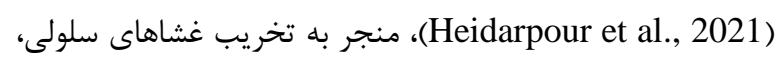
كاهش فتوسنتز و كاهش رشد كياه مى

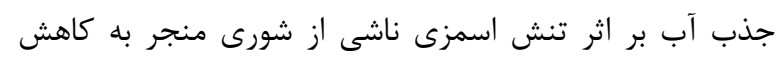

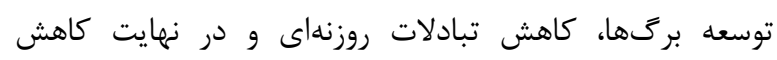
فتوسنتز بركها مىشود (Ahmad et al., 2013). در اين ميان تونان

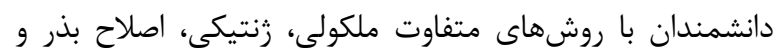

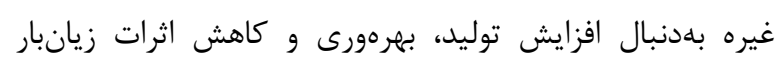

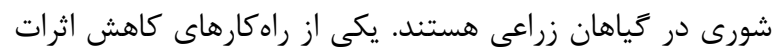

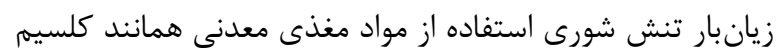

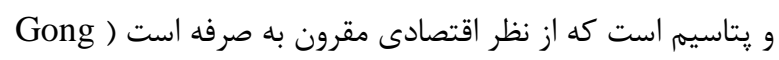

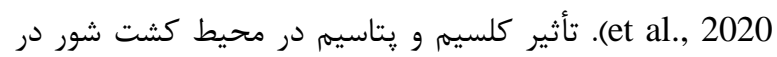

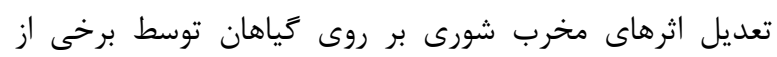

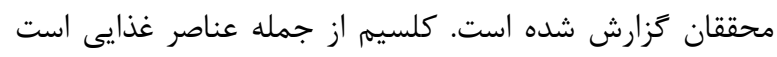

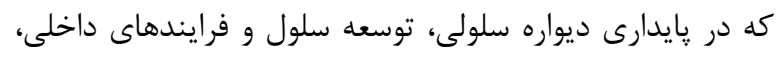

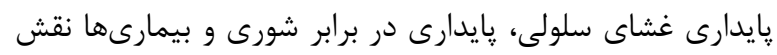

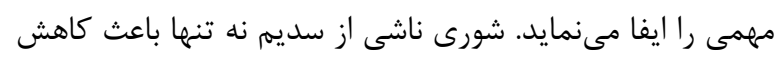

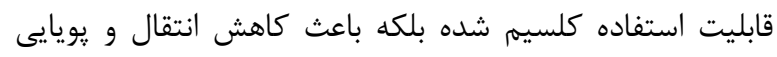

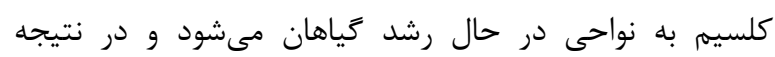
كيفيت و رشد اندامهاى رويشى و زايشى را دان تحت تأثير قرار ميدهد )

شورى خاك در اثر آبيارى، زهكشى نامناسب، يِيشروى دريا

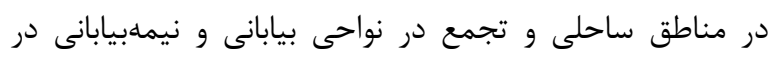

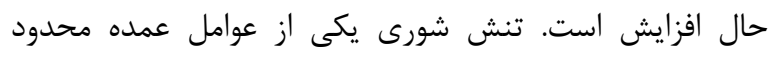

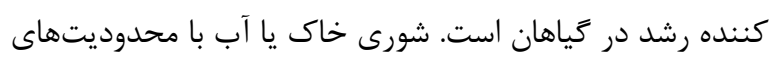

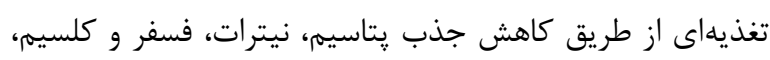

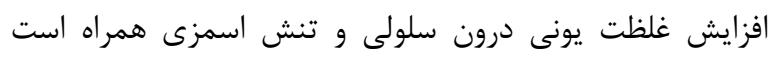

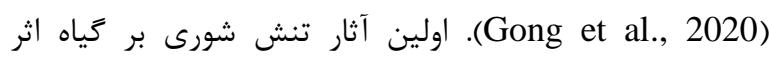

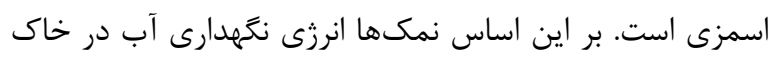

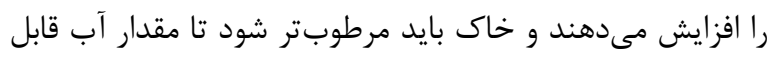

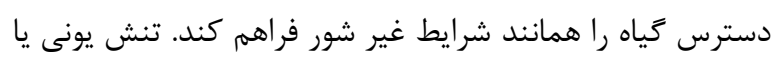

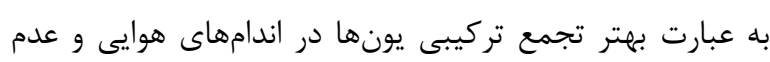

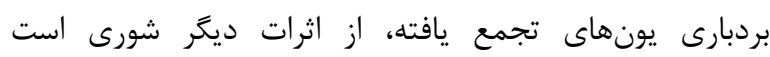
(Ahmad et al., 2013; Hasanuzzaman et al., 2018) ميان كاتيونها و آنيونها، يونهاى سديم و كلريد سميت ويزهاى

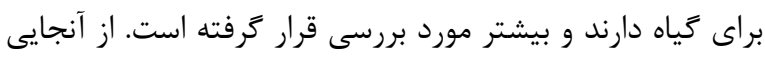

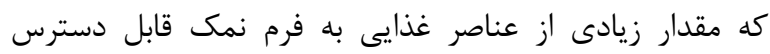

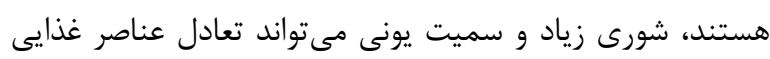

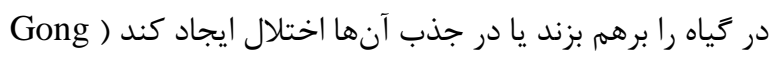
et al., 2020 أب (Nejadhabibvash \& Rezaee, 2021)

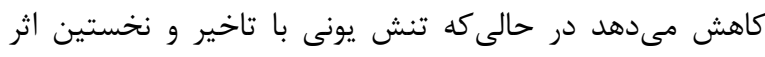

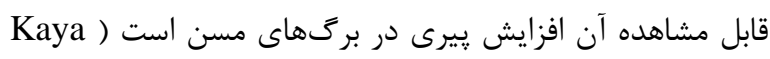
طet al., 2009

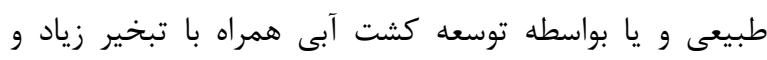

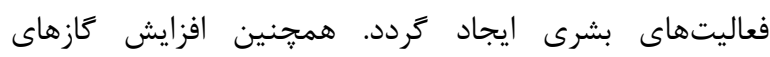

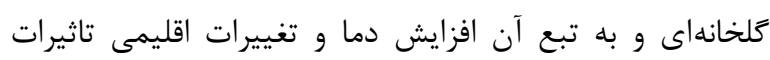

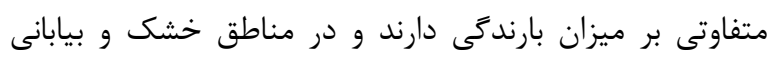

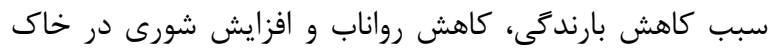

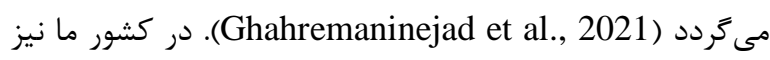
اراضى بهدليل تكيه بر كشاورزى فارياب براى توليد محصولات كشاورزى به شدت در معرض شور شدن است. بيشتر كياهان 
به منظور تهويه و زهكشى، تعداد F عدد سوراخ در كف كلدانها

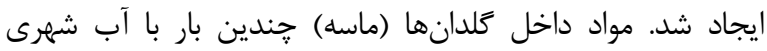

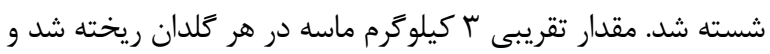
نشاهاى گوجهفرنكى رقم HAVANA در مرحله ه بركى به كلدان-

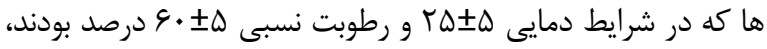

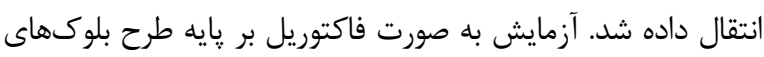

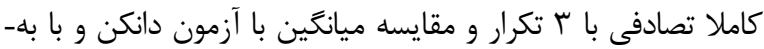
كاركيرى نرمافزار SAS (نسخه f, (9) مورد تجزيه و تحليل آمارى

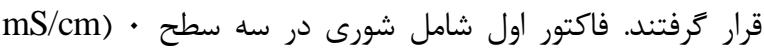

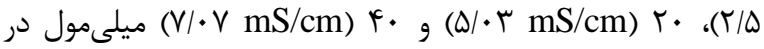

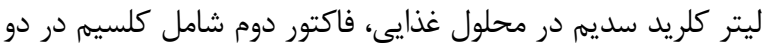

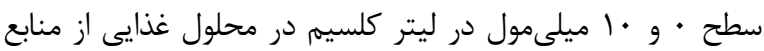

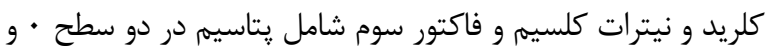
ها ميلىمول در ليتر يتاسيم در محلول غذايى از منابع كلريد و

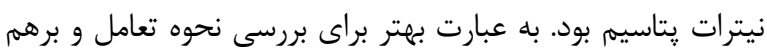

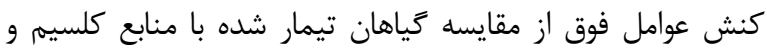
يتاسيم در محيط فاقد تنش شورى (شاهد مثبت) و كياهان تيمار

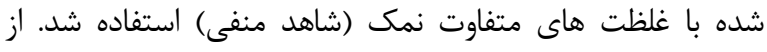

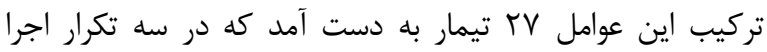

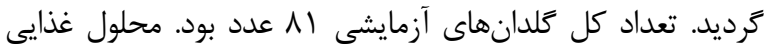

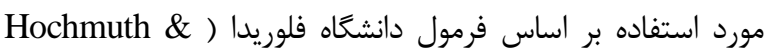
Hochmuth, 2001 •ه ميلىليتر در هر بار به هر كلدان داده شد. از اين رو در اين

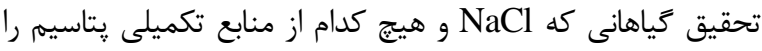

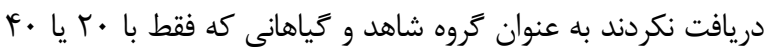

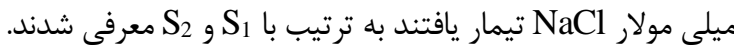

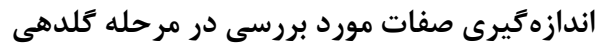

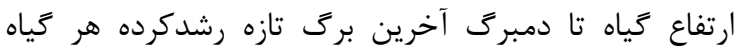

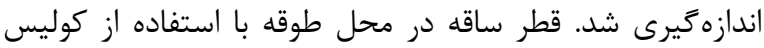

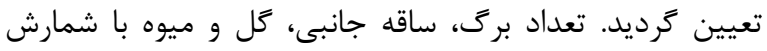
دستى تعيين شد. شاخص كلروفيل برى با دستخاه كلروفيلمتر ساخت شركت Minolta (SPAD)

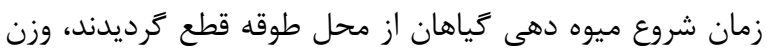

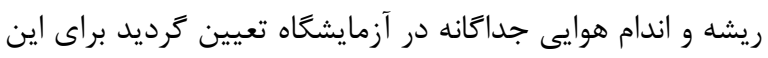
منظور نمونههاى كياهى بلمدات

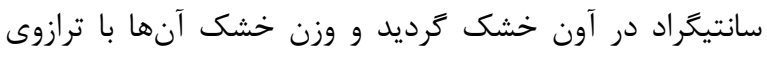

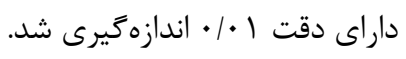

اندازهگيرى عناصر سديم، يتاسيم و كلسيم

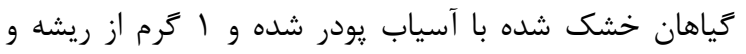
اندام هوايى خشك شده براى اندازهيرى سديم، يتاسيم و
2018). شواهد زيادى وجود دارد كه كاربرد كلسيم علائم سميت سديم را در كونههاى كياهى از بين معبرد. كلسيم با بإيدارى دارى

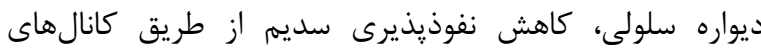

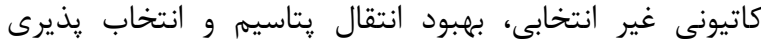

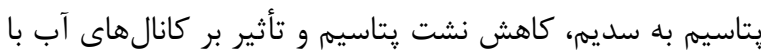
تنش شورى مقابله مى كند ( Ahmad et al., 2013; Gong et غذإ al., 2020 مطالعات نشان داد تيمار كلسيم كمبودهاى مواد

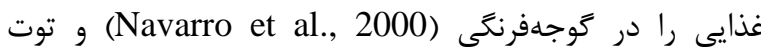
فرنكى اصلاح و باعث افزايش رشد و و عملكرد در شرايط تنش

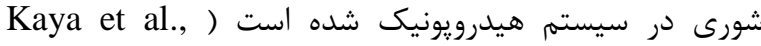

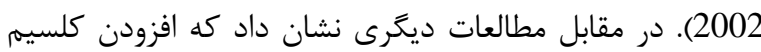

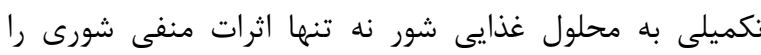
كاهش نداد بلكه باعث افزايش اثرات شورى بر خصوصيات رشدى ندى نداته توتفرنغى شده است (Mazloomi et al., 2011). يتاسيم نهتنها براى رشد طبيعى كياه ضرورى است بلكه عنصر غذايى بسيار مهمم در تنظيم فشار اسمزى و كيفيت ميوه

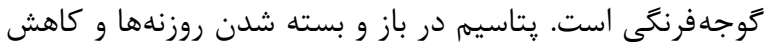
جذب سديم در شرايط تنش شورى دخالت دارد ( Ahmad et

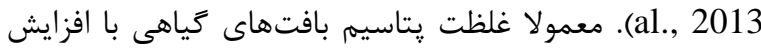

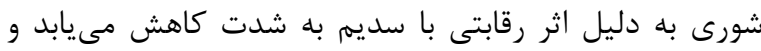

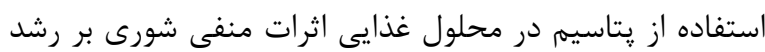

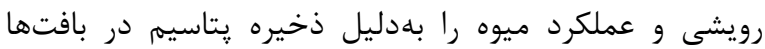
Cuartero et al., 2006; Gong et al., ) برطرف مي كنى 2020). در مقابل، مطالعات بر روى كياهان مختلف از جمله كلرنگ (Carthamus tinctorius) نشان داده است كه غلظت

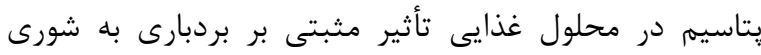

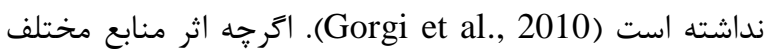
بتاسيم يا كلسيم بلهصورت جداكانه بر روى كياهان مختلف انجام شده است اما كاربرد همزمان آنها كمتر در كياه كوجه فرنكى بررسى شده است. با توجه به اهميت اقتصادى كياه

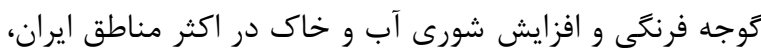
هدف از اين مطالعه بررسى اثرات منابع متفاوت كلسيم و ودابي

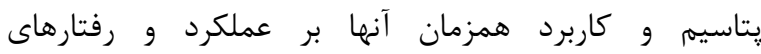
فيزيولوزيكى كياه كوجه فرنتى تحت تنش شورى بود.

$$
\text { مواد و روش ها }
$$
كشت كياه و طراحى آزمايش به منظور بررسى اثرات منابع كلسيم و يتاسيم بر عملكرد و و

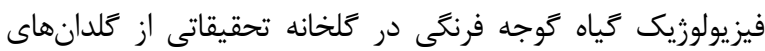

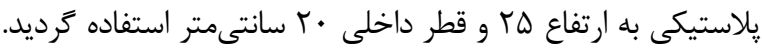


ساقه در محيط فاقد NaCl در مقايسه با گروه شاهد شد. با اين

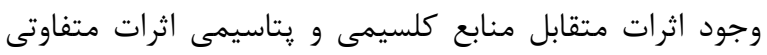

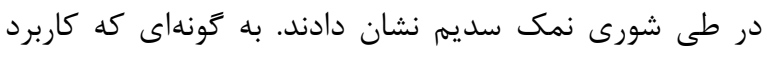

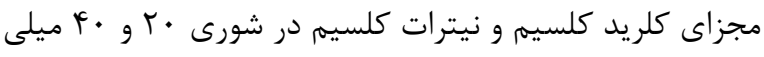

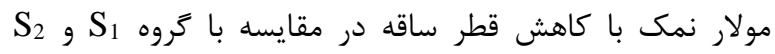

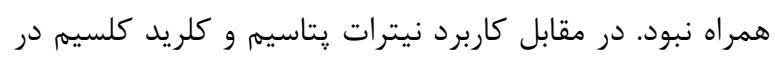

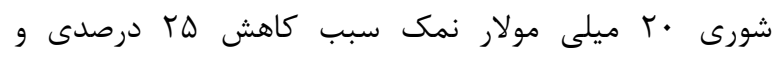

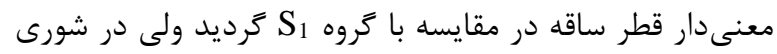

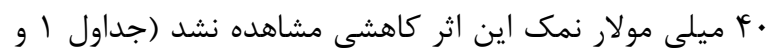

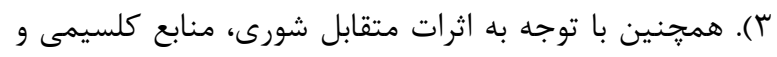

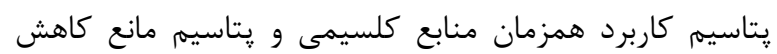
قطر ساقه در شرايط تنش شد (شكل (1).

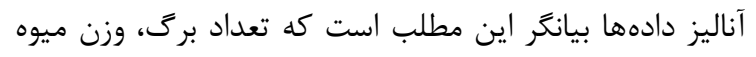

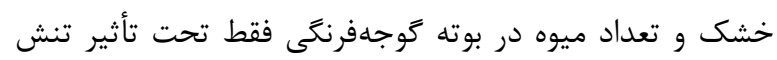

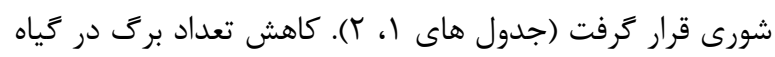

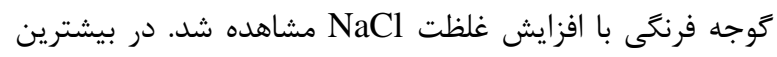

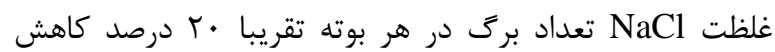

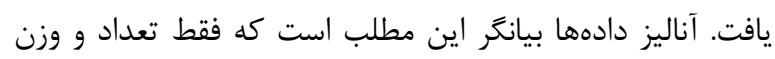

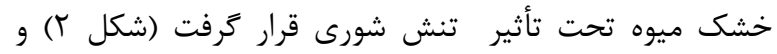

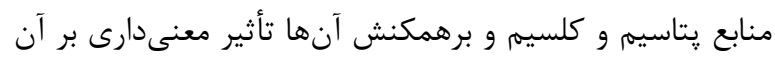

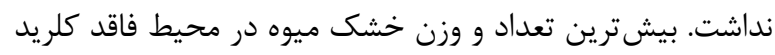

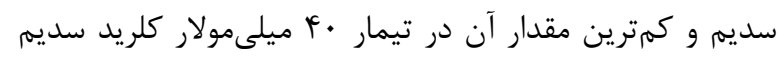

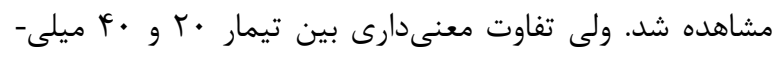

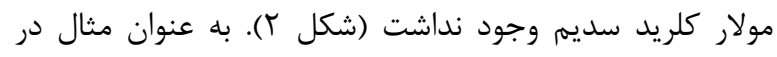

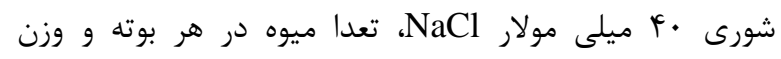
خشك ميوه به ترتيب لV و ه D درصد كاهش يافت.

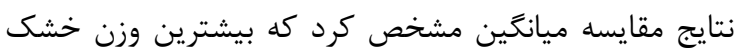

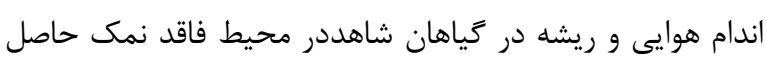

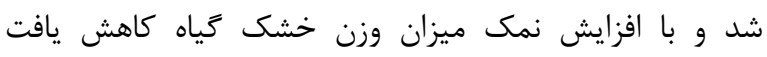

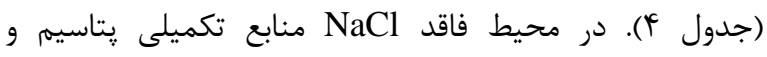

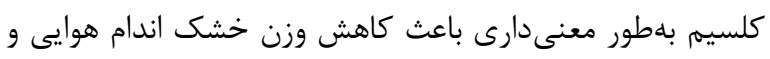

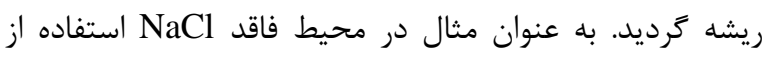

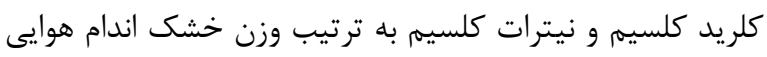

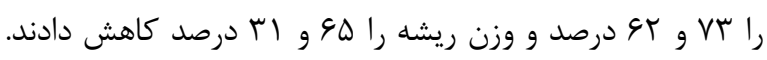

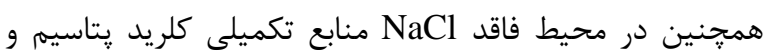

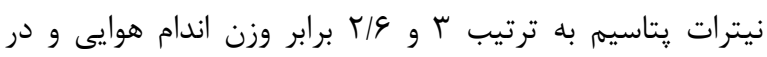

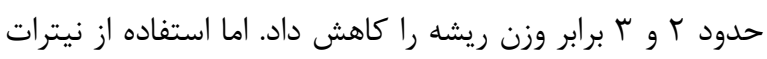

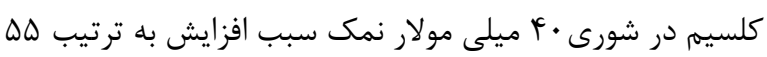

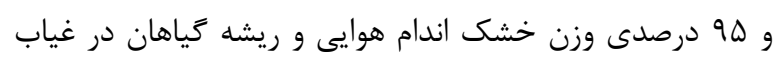

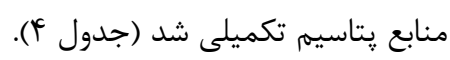

كلسيم در بوتهجينى ريخته و به مدت دو ساعت در دماى لهائ

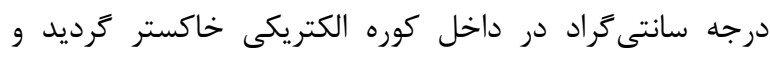

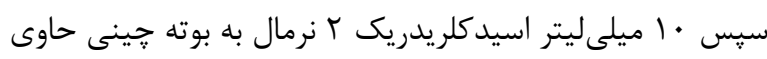

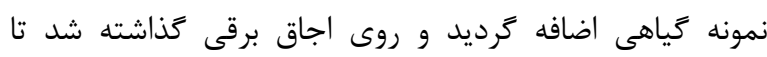

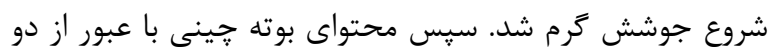

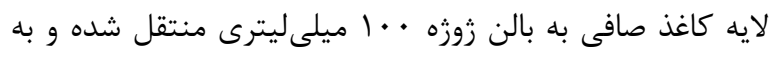

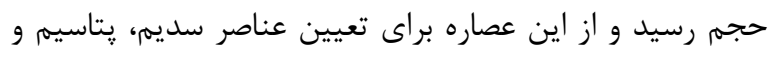

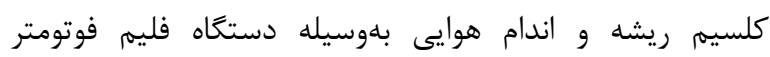

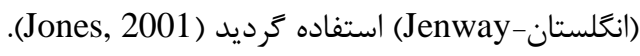

\section{نتايج}

\section{رشد و عملكرد كوجه فرنكى}

جدول هاى ا و ب نتايج تجزيه واريانس تأثير شورى، منابع

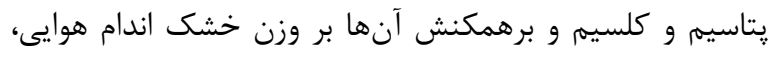

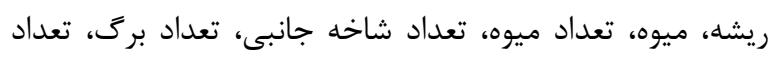

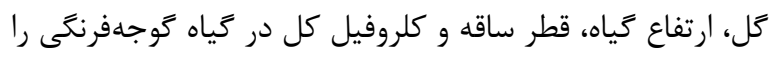

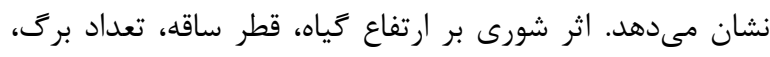

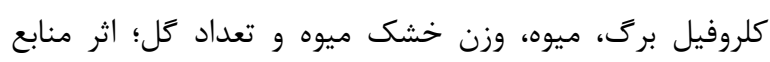

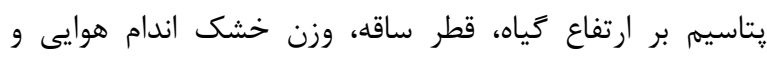
ريشه، تعداد كل و كلروفيل برك، اثر منابع كلسيم بر قطر ساقده

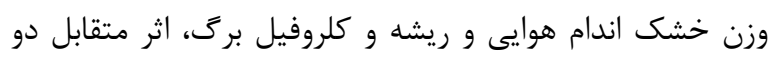

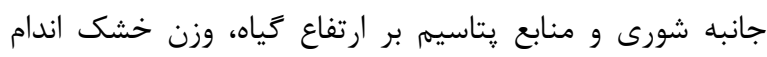

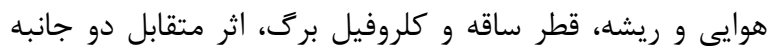

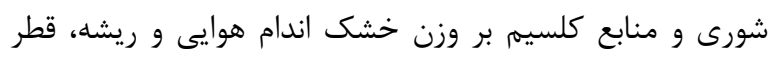

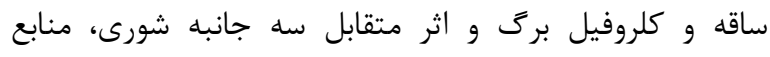

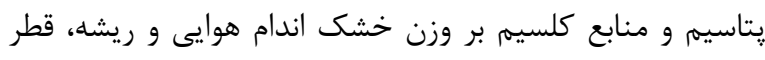

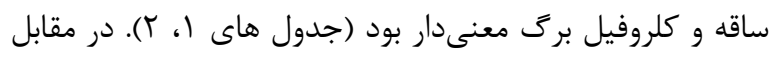

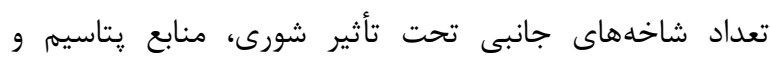

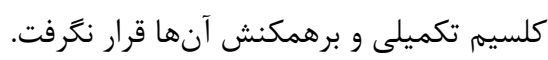

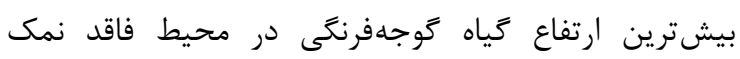

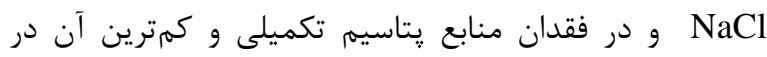
بيشترين غلظت نمك NaCl مشاهده شد. ارتفاع گياهان تيمار

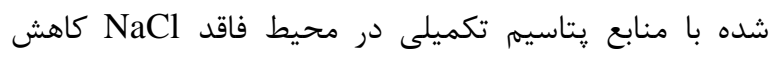
يافت ولى در محيط واجد

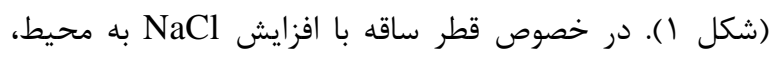
قطر ساقه كاهش يافت و بيشترين قطر ساقه در خياهان شاهد

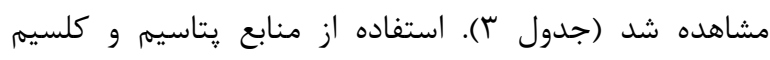

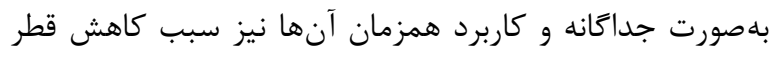

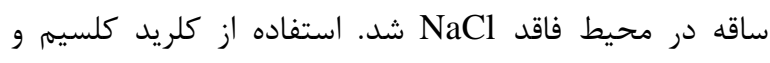

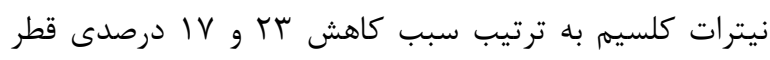


جدول ا- نتايج تجزيه واريانس تأثير شورى، منابع يتاسيم و كلسيم تكميلى بر شاخصهاى رشد كياه كوجهفرنگى(

Table 1. Results of variance analysis of the salinity, potassium and supplemental calcium sources effects on tomato plant growth parameters $(* \mathrm{p}<0.05, * * \mathrm{p}<0.01)$.

\begin{tabular}{|c|c|c|c|c|c|c|c|}
\hline \multicolumn{6}{|c|}{$\begin{array}{l}\text { ميانگَين مربعات } \\
\text { Mean square }\end{array}$} & \multirow{3}{*}{$\begin{array}{c}\text { آزادى } \\
\text { df } \\
\text { df }\end{array}$} & \multirow[t]{3}{*}{$\begin{array}{l}\text { منابع تغيير } \\
\text { (Sources) }\end{array}$} \\
\hline تعداد كل & كلروفيل كل & تعداد برى & تعداد شاخه جانبى & قطر ساقه & ارتفاع گَياه & & \\
\hline $\begin{array}{l}\text { Number of } \\
\text { flowers }\end{array}$ & $\begin{array}{c}\text { Total } \\
\text { chlorophyll }\end{array}$ & $\begin{array}{c}\text { Number of } \\
\text { leaves }\end{array}$ & $\begin{array}{c}\text { Number of } \\
\text { branches }\end{array}$ & $\begin{array}{c}\text { Stem } \\
\text { diameter }\end{array}$ & $\begin{array}{c}\text { Plant } \\
\text { height }\end{array}$ & & \\
\hline $123.25 * *$ & $2553.06^{* * * *}$ & $80.60^{\text {*** }}$ & $13.37^{\mathrm{ns}}$ & $0.077^{\text {*** }}$ & $2908.03^{\text {*** }}$ & 2 & شورى (Salt) \\
\hline $34.48^{* * *}$ & $274.69^{\%}$ & $0.9^{\mathrm{ns}}$ & $21.81^{\mathrm{ns}}$ & $0.027^{\text {**: }}$ & $388.93^{* * *}$ & 2 & يتاسيم (K) \\
\hline $10.26^{\mathrm{ns}}$ & $818.07^{* * *}$ & $17.98^{\mathrm{ns}}$ & $1.81^{\mathrm{ns}}$ & $0.006^{* * *}$ & $54.71^{\mathrm{ns}}$ & 2 & كلسيم (Ca) \\
\hline $5.63^{\mathrm{ns}}$ & $161.38^{* *}$ & $1.12^{\mathrm{ns}}$ & $10.57^{\mathrm{ns}}$ & $0.011^{\text {*** }}$ & $350.63^{* *}$ & 4 & شورى× يتاسيم ( Salt×K ) \\
\hline $1.35^{\mathrm{ns}}$ & $137.84^{\text {** }}$ & $14.97^{\text {ns }}$ & $5.96^{\mathrm{ns}}$ & $0.005^{* * a}$ & $29.96^{\mathrm{ns}}$ & 4 & شورى× كلسيم ( Salt×Ca ) \\
\hline $4.06^{\mathrm{ns}}$ & $415.2^{* *}$ & $4.19^{\mathrm{ns}}$ & $8.89^{\mathrm{ns}}$ & $0.004^{\text {whas }}$ & $82.85^{\mathrm{ns}}$ & 12 & شورى× پتاسيم× كلسيم (Salt×K×Ca) \\
\hline $9.33^{\mathrm{ns}}$ & $18.41^{\mathrm{ns}}$ & $12.64^{\mathrm{ns}}$ & $9.33^{\mathrm{ns}}$ & $0.002^{\mathrm{ns}}$ & $96.77^{\text {ns }}$ & 2 & تكرار (Repeat) \\
\hline 6.59 & 30.74 & 7.10 & 10.21 & 0.001 & 45.31 & 52 & خطا (Error) \\
\hline 121.71 & 38.92 & 17.42 & 144.37 & 15.42 & 24.42 & & ضريب تغييرات (C.V) \\
\hline
\end{tabular}

جدول r - نتايج تجزيه واريانس تأثير شورى، منابع يتاسيم و كلسيم تكميلى بر عملكرد كياه كوجهفرنكى (

Table 2. Results of variance analysis of the salinity, potassium and supplemental calcium sources effects on tomato yield $(* \mathrm{p}<0.05, * * \mathrm{p}<0.01)$.

\begin{tabular}{|c|c|c|c|c|c|}
\hline \multicolumn{4}{|c|}{$\begin{array}{l}\text { ميانكين مربعات } \\
\text { Mean square }\end{array}$} & \multirow[t]{2}{*}{ درجه آزادى } & \multirow[t]{2}{*}{$\begin{array}{l}\text { منابع تغيير } \\
\text { (Sources) }\end{array}$} \\
\hline $\begin{array}{c}\text { وزن خشك ميوه } \\
\text { Fruit dry } \\
\text { weight }\end{array}$ & $\begin{array}{l}\text { تعداد ميوه } \\
\text { Numbers } \\
\text { of fruits }\end{array}$ & $\begin{array}{c}\text { وزن خشك ريشه } \\
\text { Root dry } \\
\text { weight }\end{array}$ & وزن خشك اندام هوايى & & \\
\hline $0.99^{* * *}$ & $4.46^{* * *}$ & $18.99^{\text {** }}$ & $139.9^{* * *}$ & 2 & شورى (Salt) \\
\hline $0.45^{\mathrm{ns}}$ & $1.53^{\mathrm{ns}}$ & $12.1^{* * *}$ & $104.25^{\text {w** }}$ & 2 & يتاسيم (K) \\
\hline $0.17^{\mathrm{ns}}$ & $0.61^{\mathrm{ns}}$ & $2.22^{* * *}$ & $19.5^{* * *}$ & 2 & كلسيم (Ca) \\
\hline $0.28^{\mathrm{ns}}$ & $0.53^{\mathrm{ns}}$ & $6^{* * *}$ & $43.33^{\text {*as }}$ & 4 & شورى× يتاسيم ( Salt×K ) \\
\hline $0.1^{\mathrm{ns}}$ & $0.16^{\mathrm{ns}}$ & $1.56^{\text {*ै }}$ & $10.17^{\text {was }}$ & 4 & شورى× كلسيم ( Salt×Ca ) \\
\hline $0.12^{\mathrm{ns}}$ & $0.19^{\mathrm{ns}}$ & $.65^{*}$ & $7.83^{* *}$ & 12 & شورى× بتاسيم× كلسيم (Salt×K×Ca) \\
\hline $0.29^{\mathrm{ns}}$ & $1.12^{\mathrm{ns}}$ & $0.1^{\mathrm{ns}}$ & $2.63^{\mathrm{ns}}$ & 2 & تكرار (Repeat) \\
\hline 0.18 & 0.59 & .31 & 2.06 & 52 & خطا (Error) \\
\hline 352.9 & 245.4 & 91.12 & 67.76 & & ضريب تغييرات (C.V) \\
\hline
\end{tabular}

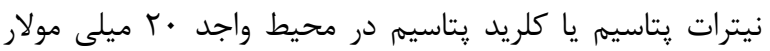

محتواى رنكيزه فتوسنتزى

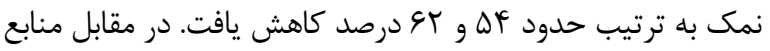

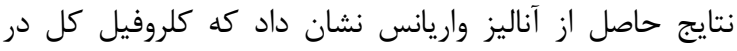

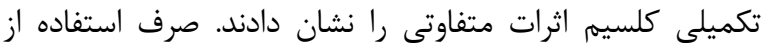

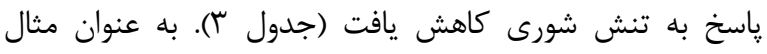

كلريد كلسيم در محيط فاقد يا واجد

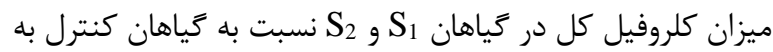

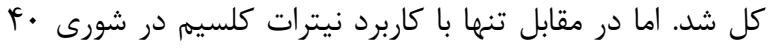

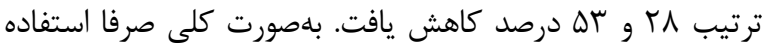

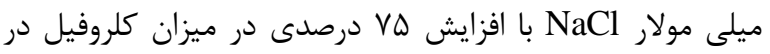

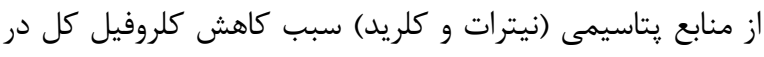

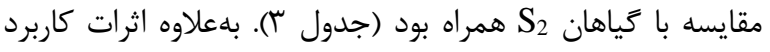

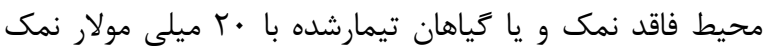
همزمان منابع يتاسيم و كلسيم بر ميزان كلروفيل معنى دار بود كه

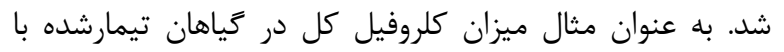




$$
\begin{aligned}
& \text { جدول بـ اثرات متقابل شورى، منابع يتاسيم و كلسيم تكميلى بر قطر ساقه و كلروفيل برك كياه كوجه فرنكى. حروف انَّليسى يكسان عدم تفاوت معنى دار در }
\end{aligned}
$$

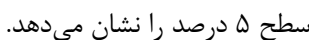

Table 3. Interaction effects of salinity, potassium and calcium sources on stem diameter and leaf chlorophyll of tomato plants. The same English letters show no significant difference at the 5\% level.

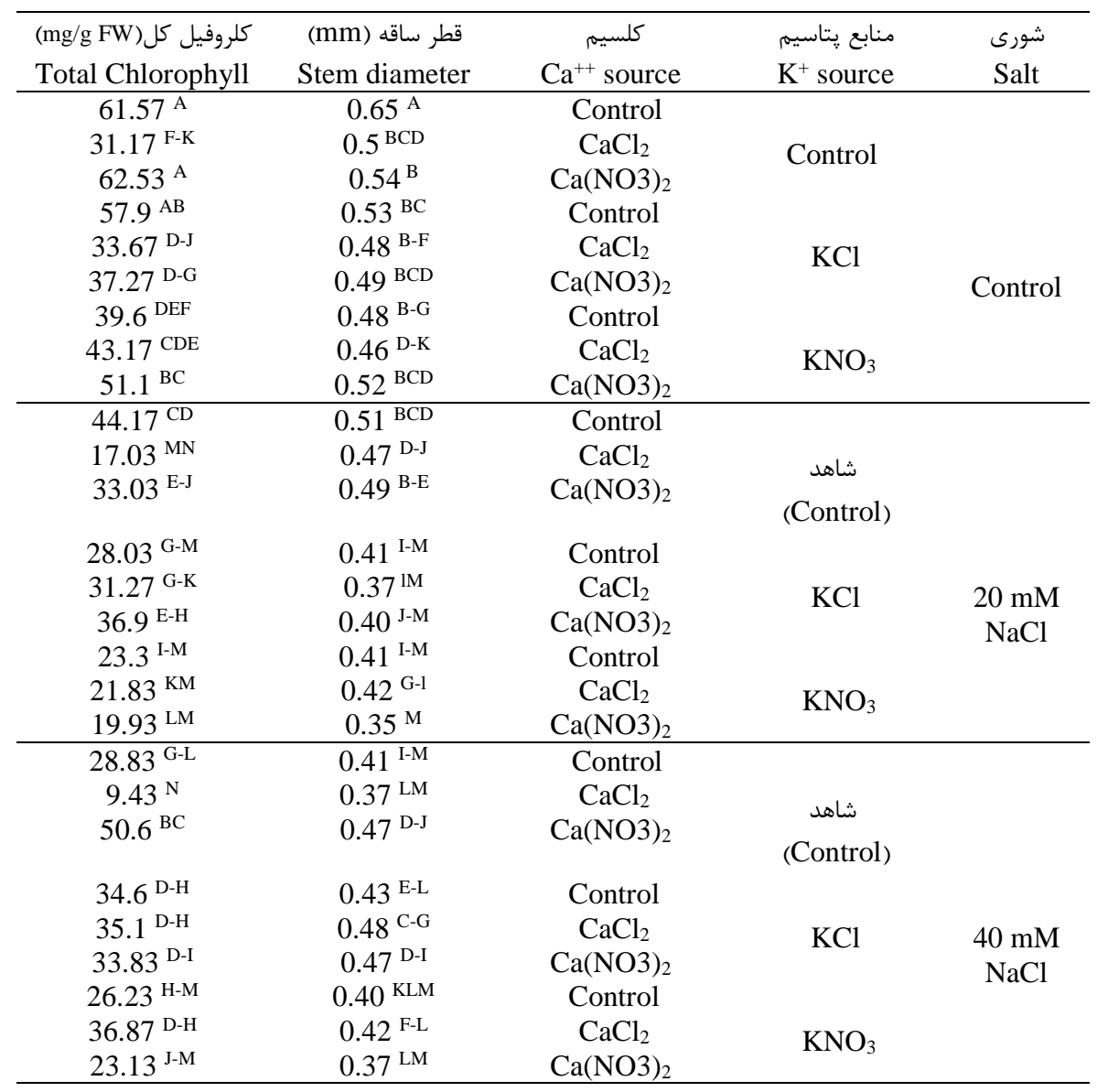

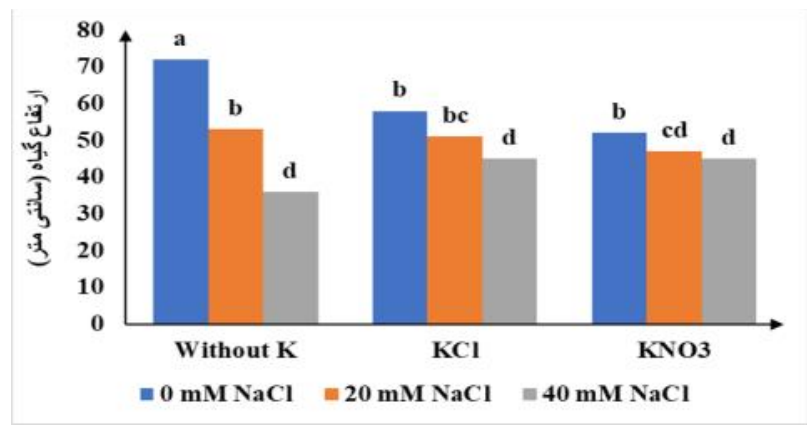

شكل ا- اثر متقابل شورى و منابع يتاسيم تكميلى بر ارتفاع كياه كوجهفرنكى. حروف انكليسى يكسان عدم تفاوت معنىدار در سطح ا درصد را نشان مىدهد. Figure 1. Interaction of salinity and potassium sources on tomato plant height. The same English letters show no significant difference at the $5 \%$ level. 

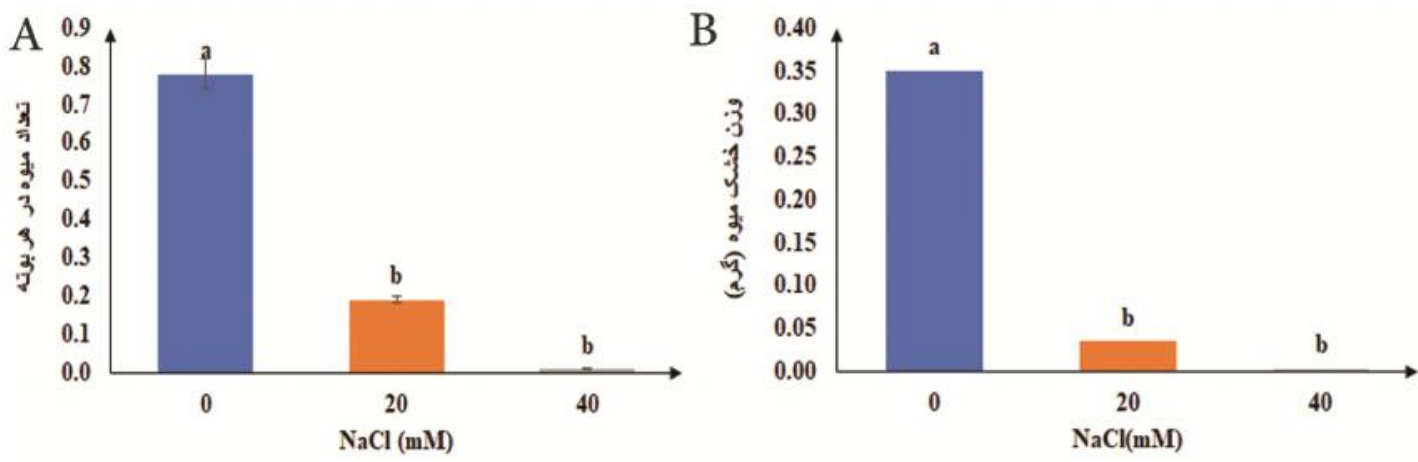

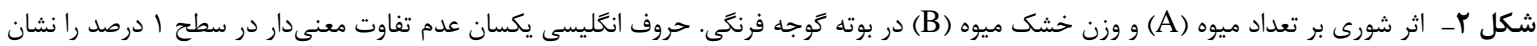

Figure 2. Effect of salinity on fruit number (A) and fruit dry weight (B) in tomato plant. The same English letters show no significant difference at the $5 \%$ level.

وابسته به غلظت نمك نوع عملكرد متفاوت بود. با اين وجود بايتاسيم نتايج تجزيه واريانس نشان داد اثر شورى و منابع يتاسيم بر

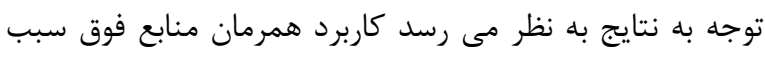
درصد يتاسيم ريشه و منابع يتاسيمى و اثر متقابل سه جانبه

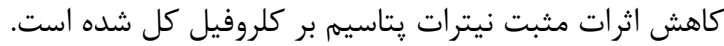

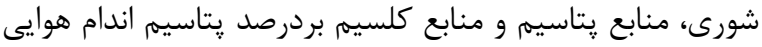

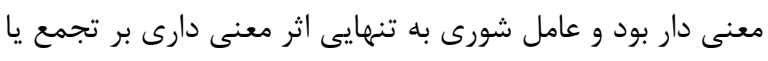

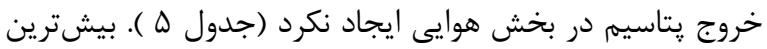
درصد يتاسيم ريشه در شورى صفر مشاهده شد و با اضافه شدن

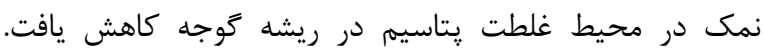
كاربرد منابع קتاسيم بهطور معنىدارى باعث افزايش درصد يتاسيم ريشه و اندام هوايى شد و در اين ميان تاثير كلريد

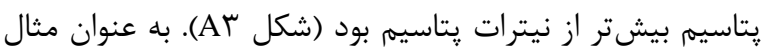

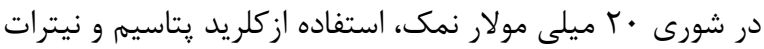

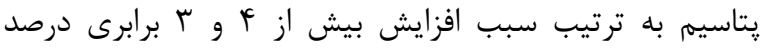

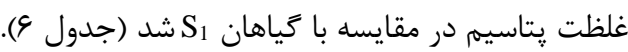
كلسيم

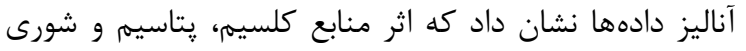

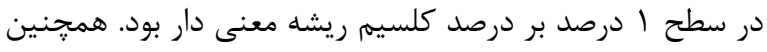

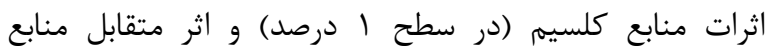
كلسيمى و شورى (در سطح ه درصد) بر ميزان كلسيم اندام

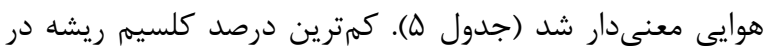

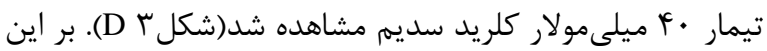
اساس بر خلاف ريشه، شورى تاثير معنى دارى بر تغييرات

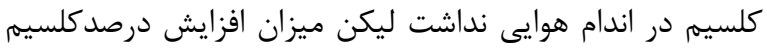

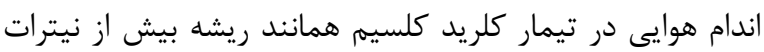

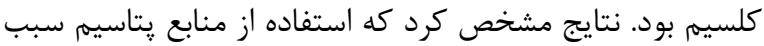
كاهش غلظت كلسيم ريشه شد ولى تفاوت معنى دارى بين تيمار

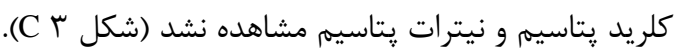

غلظت عناصر در اندامهاى گياه گوجهفرنكى

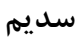
نتايج تجزيه واريانس نشان داد اثر شورى و منابع يتاسيم بر درصد غلظت سديم ريشه و بخش هوايى كياه گوجه فرنكى معنى

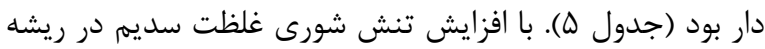

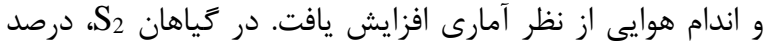

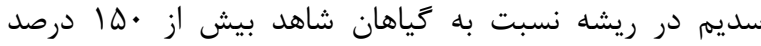

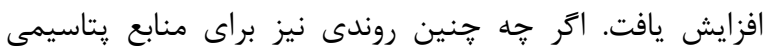

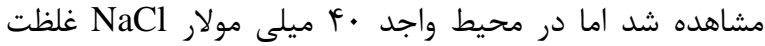
سديم در كياهانى كه فقط با كلريد يتاسيم يا نيترات يتاسيم

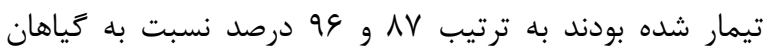
شاهد افزايش يافته بود ولى با گياهان S2 اختلاف معنى دارى

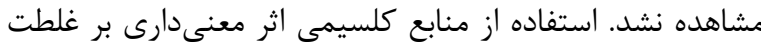

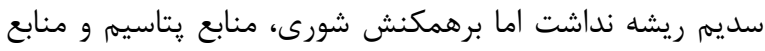

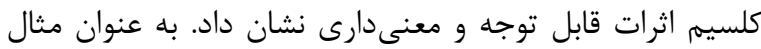

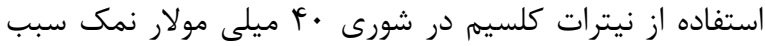

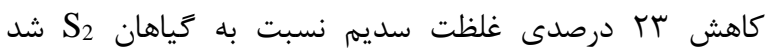

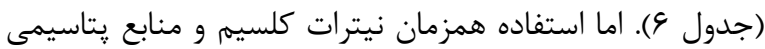

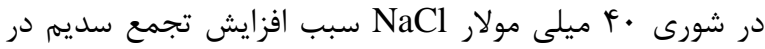

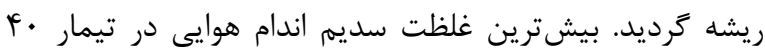

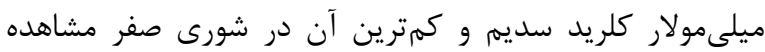

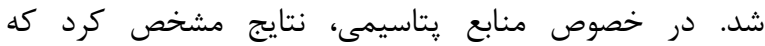
بيشترين غلظت سديم اندام هوايى با كاربرد نيترات يتاسيم

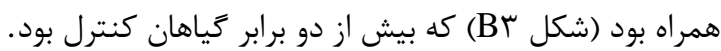


جدول F- اثرات متقابل شورى، منابع يتاسيم و كلسيم تكميلى بر وزن خشك اندام هوايى و ريشه. حروف انگليسى يكسان عدم تفاوت معنى دار در سطح ه درصد را نشان مى دهد.

Table 4. Interaction effects of salinity, potassium and calcium sources on shoot and root dry weight. The same English letters show no significant difference at the $5 \%$ level.

\begin{tabular}{|c|c|c|c|c|}
\hline $\begin{array}{c}\text { وزن خشك ريشه } \\
\text { Shoot dry weight } \\
\text { (g) }\end{array}$ & $\begin{array}{c}\text { وزن خشكاندامهوايى } \\
\text { Shoot dry weight } \\
\text { (g) }\end{array}$ & كلسيهم $\mathrm{Ca}^{++}$source & $\begin{array}{l}\text { منابع يتاسيم } \\
\mathrm{K}^{+} \text {source }\end{array}$ & ش \\
\hline $5.25^{\mathrm{A}}$ & $16.91^{\mathrm{A}}$ & Control & \multirow{4}{*}{ Control } & \multirow{9}{*}{ Control } \\
\hline $3.18^{\mathrm{BC}}$ & $9.76^{\mathrm{BC}}$ & $\mathrm{CaCl}_{2}$ & & \\
\hline $3.99^{\mathrm{B}}$ & $10.44^{\mathrm{B}}$ & $\mathrm{Ca}(\mathrm{NO} 3)_{2}$ & & \\
\hline $2.56^{\mathrm{CD}}$ & $5.65^{\mathrm{D}-\mathrm{G}}$ & Control & & \\
\hline $1.41^{\mathrm{EFG}}$ & $5.96^{\mathrm{D}-\mathrm{G}}$ & $\mathrm{CaCl}_{2}$ & \multirow{3}{*}{$\mathrm{KCl}$} & \\
\hline $0.88^{\mathrm{E}-\mathrm{H}}$ & $3.89^{\mathrm{F}-\mathrm{I}}$ & $\mathrm{Ca}(\mathrm{NO} 3)_{2}$ & & \\
\hline $1.67 \mathrm{DEF}$ & $6.35^{\mathrm{DEF}}$ & Control & & \\
\hline $1.25 \mathrm{E}-\mathrm{H}$ & $5.92^{\mathrm{D}-\mathrm{G}}$ & $\mathrm{CaCl}_{2}$ & \multirow{2}{*}{$\mathrm{KNO}_{3}$} & \\
\hline $0.62^{\mathrm{FGH}}$ & $2.47 \mathrm{IJ}$ & $\mathrm{Ca}(\mathrm{NO} 3)_{2}$ & & \\
\hline $1.4^{\mathrm{EFG}}$ & $7.75^{\mathrm{CD}}$ & Control & \multirow{4}{*}{ Control } & \multirow{9}{*}{$\begin{array}{c}20 \mathrm{mM} \\
\mathrm{NaCl}\end{array}$} \\
\hline $1.06^{\mathrm{E}-\mathrm{H}}$ & $5.86^{\mathrm{D}-\mathrm{G}}$ & $\mathrm{CaCl}_{2}$ & & \\
\hline $1.42 \mathrm{EFG}$ & $6.74^{\mathrm{DE}}$ & $\mathrm{Ca}(\mathrm{NO} 3)_{2}$ & & \\
\hline $0.8^{\text {E-H }}$ & $3.54^{\mathrm{F}-\mathrm{J}}$ & Control & & \\
\hline $0.68^{\mathrm{FGH}}$ & $4.08^{\mathrm{E}-\mathrm{I}}$ & $\mathrm{CaCl}_{2}$ & \multirow{3}{*}{$\mathrm{KCl}$} & \\
\hline $1.31^{\mathrm{E}-\mathrm{H}}$ & $5.4^{\mathrm{D}-\mathrm{H}}$ & $\mathrm{Ca}(\mathrm{NO} 3)_{2}$ & & \\
\hline $0.92^{\mathrm{E}-\mathrm{H}}$ & $3.85^{\mathrm{F}-\mathrm{I}}$ & Control & & \\
\hline $0.6^{\mathrm{FGH}}$ & $3.55^{\text {F-J }}$ & $\mathrm{CaCl}_{2}$ & \multirow{2}{*}{$\mathrm{KNO}_{3}$} & \\
\hline $0.37 \mathrm{GH}$ & $2.41^{\mathrm{IJ}}$ & $\mathrm{Ca}(\mathrm{NO} 3)_{2}$ & & \\
\hline $0.6^{\mathrm{FGH}}$ & $2.7 \mathrm{HIJ}$ & Control & \multirow{3}{*}{ Control } & \multirow{9}{*}{$\begin{array}{c}40 \mathrm{mM} \\
\mathrm{NaCl}\end{array}$} \\
\hline $0.24^{\mathrm{H}}$ & $1.7 \mathrm{IJ}$ & $\mathrm{CaCl}_{2}$ & & \\
\hline $1.77^{\mathrm{DE}}$ & $4.2^{\mathrm{E}-\mathrm{I}}$ & $\mathrm{Ca}(\mathrm{NO} 3)_{2}$ & & \\
\hline $1.00^{\mathrm{E}-\mathrm{H}}$ & $3.22^{\mathrm{G}-\mathrm{J}}$ & Control & \multirow{4}{*}{$\mathrm{KCl}$} & \\
\hline $0.71^{\mathrm{E}-\mathrm{H}}$ & $4.13^{\mathrm{E}-\mathrm{I}}$ & $\mathrm{CaCl}_{2}$ & & \\
\hline $0.72^{\mathrm{E}-\mathrm{H}}$ & $1.05^{\mathrm{J}}$ & $\mathrm{Ca}(\mathrm{NO} 3)_{2}$ & & \\
\hline $0.81^{\mathrm{E}-\mathrm{H}}$ & $3.79^{\mathrm{F}-\mathrm{J}}$ & Control & & \\
\hline $0.83^{\mathrm{E}-\mathrm{H}}$ & $3.85^{\mathrm{F}-\mathrm{I}}$ & $\mathrm{CaCl}_{2}$ & \multirow{2}{*}{$\mathrm{KNO}_{3}$} & \\
\hline $0.35^{\mathrm{GH}}$ & $1.96^{\mathrm{IJ}}$ & $\mathrm{Ca}(\mathrm{NO} 3)_{2}$ & & \\
\hline
\end{tabular}

جيبرلين و اكسين و بالطبع كاهش تقسيم سلولى باعث كاهش رشد و

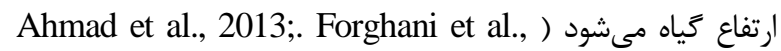
(2020

بنابراين علاوه بر رتانسيل آبى و سميت يونها، كاهش ارتقاع و رشد

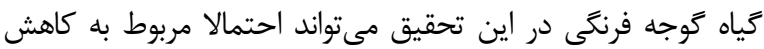
فيتوهورمونهاى مذكور نيز باشد. استفاده از منابع متفاوت يتاسيم و

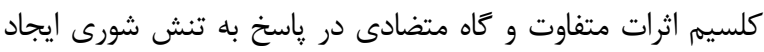

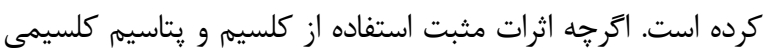
در برخى از موارد مشاهده شده است اما نتايج تحقيقات مظلومى و همكاران (Mazloomi et al., 2011) نشان داد كه كاربرد كلسيم تكميلى توام با شورى وزن خشك اندامهوايى و ريشه توت فرنكى را كاهش داد و كاربرد كلسيم تكميلى در كاهش آثار منفى شورى موثر نبود و حتى در كاربرد همزمان شورى و كلسيم تكميلى، كلسيم تكميلى اثرات منفى شورى را تشديد كرد و بيشترين كرد كاهش عملكرد ودرد در افزودن توام كلسيم و شورى به تيمارها بهدست آمد. اين تحقيق
در اين مطالعه ياسخهاى برخى صفات رويشى، فيزيولوزى و ميزان

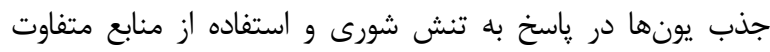
يتاسيم و كلسيم براى كاهش اثرات تنش شورى بررسى شد. به عنوان

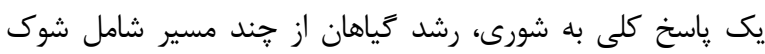

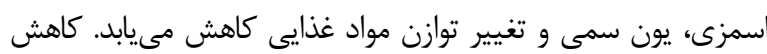

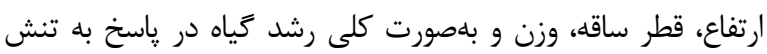

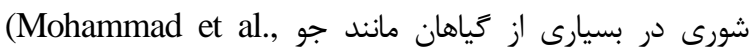

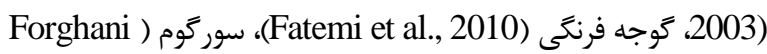
كزارش شده است. كاهش رشد، وزن خشك اندام (et al., 2018 هوايى و ريشه گياه در سطوح بالاى شورى به عدم توسعه ريشه گياه،

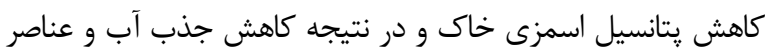
غذايى و افزايش سميت يونهاى كلر و سديم نسبت داده مىشود (Ahmad et al., 2013; Hasanuzzaman et al., 2018) همجنين تحقيقات مشخص كرده است كه شورى با كاهش سطح 
جدول ه- نتايج تجزيه واريانس تاثير شورى، منابع پتاسيم و كلسيم تكميلى بر غلظت عناصر ريشه و اندام هوايى كياه گوجهفرنگى (

Table 5. Results of variance analysis of the salinity, potassium and calcium sources effects on root and shoot ions tomato plants $(* \mathrm{p}<0.05, * * \mathrm{p}<0.01)$.

\begin{tabular}{|c|c|c|c|c|c|c|c|}
\hline \multicolumn{6}{|c|}{$\begin{array}{l}\text { ميانخين مربعات } \\
\text { Mean square }\end{array}$} & \multirow{3}{*}{$\begin{array}{c}\text { درادى } \\
\text { آرجه } \\
\text { df }\end{array}$} & \multirow{3}{*}{$\begin{array}{l}\text { منابع تغيير } \\
\text { (Sources) }\end{array}$} \\
\hline \multicolumn{3}{|c|}{ ساقه } & \multicolumn{3}{|c|}{ ريشه } & & \\
\hline كلسيم & يتاسيم & سديم & كلسيم & يتاسيم & سديم & & \\
\hline $\mathrm{Ca}^{++}$ & $\mathrm{K}^{+}$ & $\mathrm{Na}^{+}$ & $\mathrm{Ca}^{++}$ & $\mathrm{K}^{+}$ & $\mathrm{Na}^{+}$ & & \\
\hline $0.72^{\mathrm{ns}}$ & $0.29^{\mathrm{ns}}$ & $18.88^{* *}$ & $0.48^{\text {*** }}$ & $0.53^{\text {絽 }}$ & $12.58^{\text {券拳 }}$ & t & شورى(Salt) \\
\hline $0.64^{\mathrm{ns}}$ & $32.66^{\text {䖭 }}$ & $1.20^{*}$ & $0.29^{* *}$ & $4.92^{\text {**: }}$ & 1.57 & r & يتاسيم (K) \\
\hline $34.40^{* * *}$ & $1.59^{\mathrm{ns}}$ & $0.04^{\mathrm{ns}}$ & $6.35 * *$ & $0.25^{\mathrm{ns}}$ & $0.59^{\mathrm{ns}}$ & r & كلسيم (Ca) \\
\hline $2.04^{\mathrm{ns}}$ & $0.42^{\mathrm{ns}}$ & $0.46^{\mathrm{ns}}$ & $0.026^{\mathrm{ns}}$ & $0.19^{\text {ns }}$ & $0.24^{\mathrm{ns}}$ & f & شورى× يتاسيم (Salt×K) \\
\hline $6.94^{*}$ & $0.71^{\mathrm{ns}}$ & $0.25^{\mathrm{ns}}$ & $0.115^{\mathrm{ns}}$ & $0.007^{\mathrm{ns}}$ & $0.19^{\mathrm{ns}}$ & f & شورى × كلسيم (Salt×Ca) \\
\hline $1.74^{\mathrm{ns}}$ & $1.79^{* *}$ & $0.34^{\mathrm{ns}}$ & $0.047^{\mathrm{ns}}$ & $0.115^{\mathrm{ns}}$ & $1.43^{\text {*\% }}$ & ir & شورى× يتاسيم× كلسيم \\
\hline $7.34^{\mathrm{ns}}$ & $0.05^{\mathrm{ns}}$ & $0.03^{\mathrm{ns}}$ & $0.011^{\mathrm{ns}}$ & $0.104^{\mathrm{ns}}$ & $0.56^{\mathrm{ns}}$ & r & تكرار(Repeat) \\
\hline 2.44 & 0.65 & 0.24 & 0.045 & 0.098 & 0.44 & $\Delta r$ & خطا (Error) \\
\hline 41.46 & 64.04 & 39.53 & 33.84 & 39.53 & 39.15 & & ضريب تغييرات \\
\hline
\end{tabular}
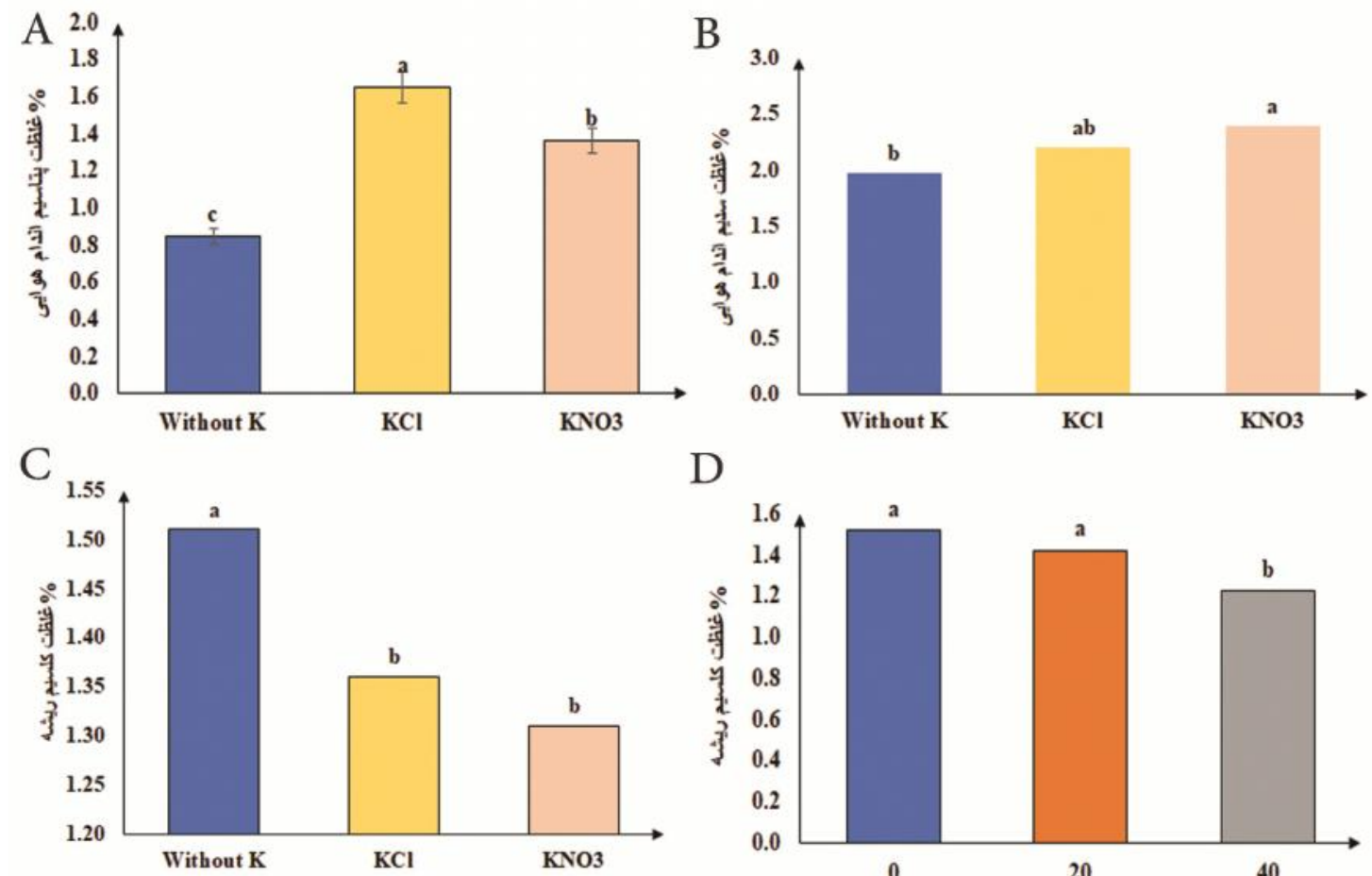

D

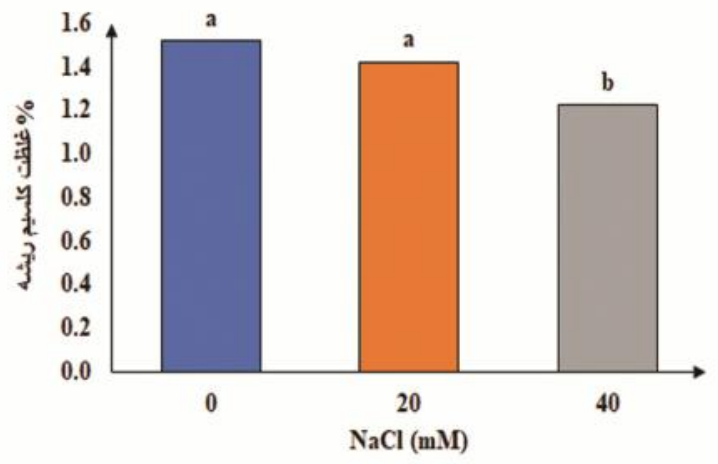

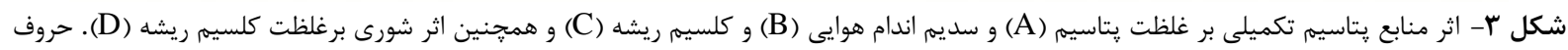

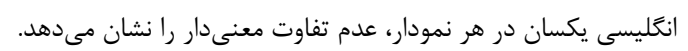

Figure 3. Effect of potassium sources on accumulation potassium (A) and sodium (B) in shoot and calcium in root (C) as well as effects of salinity on root calcium concentration (E). The same English letters in each chart show no significant difference. 
Forghani et al. The effects of K and Ca on tomatoes under salinity stress فرقانى و همكاران. اثرات يتاسيم و كلسيم بر كوجافرنكى تحت تنش شورى

جدول 9- اثرات متقابل شورى، منابع هتاسيم و كلسيم تكميلى بر غلظت سديم ريشه و يتاسيم اندام هوايى. حروف انخليسى يكسان در هر نمودار، عدم تفاوت معنى دار را نشان مىدهد.

Table 6. Interaction effects of salinity, potassium and calcium sources on root sodium and shoot potassium concentrations. The same English letters in each chart show no significant difference.

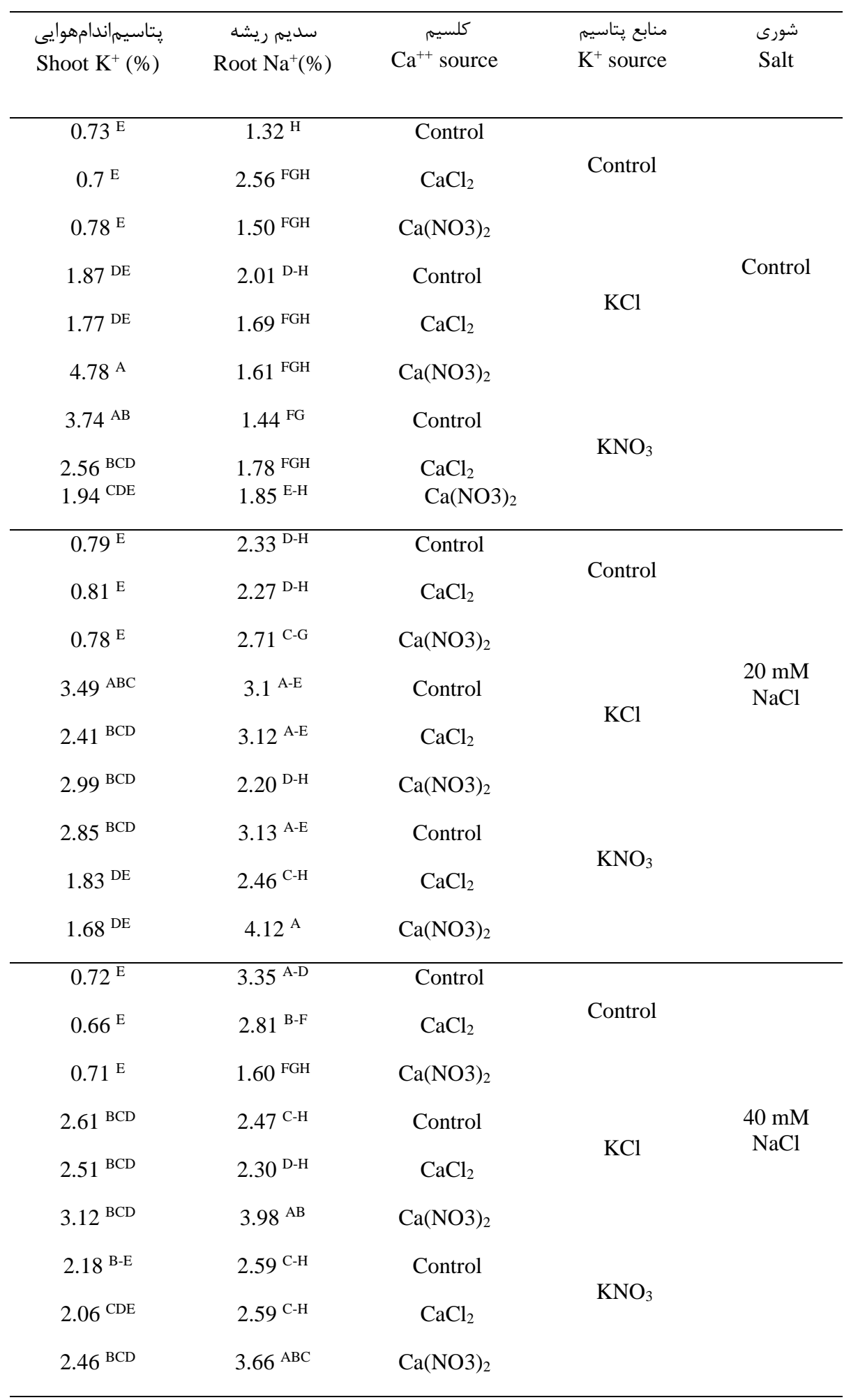


و پيتاسيم بر ارتفاع، قطر و رشد گياه وابسته به گونه و شدت تنش

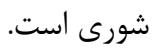

در خصوص وزن ميوه به نظر مىرسد كه تنش شورى توانايى

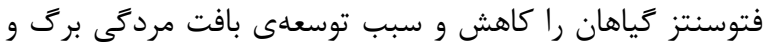

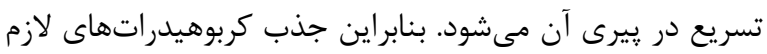
براى توليد ميوه كاهش مىيابد (Cuartero et al., 2006). كزارشهاى متعددى از كاهش ميزان فتوسنتز و محتواى كلروفيل بركها تحت تنش شورى وجود دارد ( Ahmad et al.,

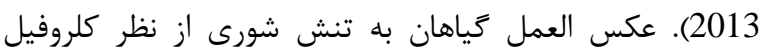

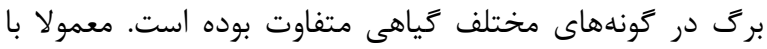
افزايش شورى ميزان شاخص كلروفيل برى هماند اين تحقيق

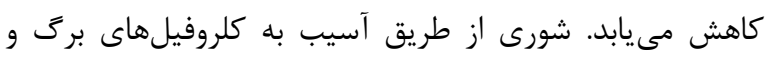

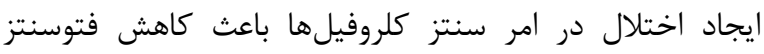
مىشود ) Abogadallah, 2010; Hasanuzzaman et al., 2018). در ارزيابى سوركوم در شرايط تنش شورى، كاهش و

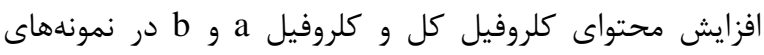
مورد آزمايش كزارش شده است (Forghani et al., 2018).

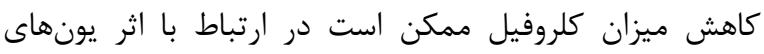
كلريد و سديم بر ميزان عناصر غذايى ضرورى باشد. كاهش آند آهن،

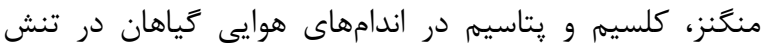

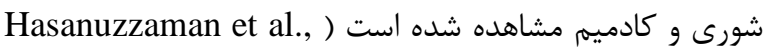
2018). همجنين كاهش غلظت كلروفيل در كياهان تحت تنش ممكن است در ارتباط با افزايش فعاليت تجزيه كلروفيل توسط

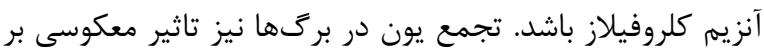
غلظت كلروفيل دارد (Ahmad et al., 2013). محققان ( Kochia تاييد نمودند كه كاربرد كلسيم در (et al., 2013 scoparia

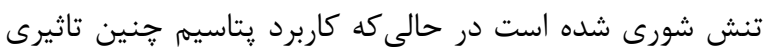
نداشت. مطابق با اين نتايج كاربرد نيترات كلسيم در بالاترين

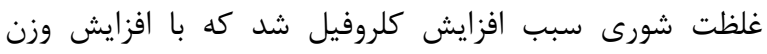

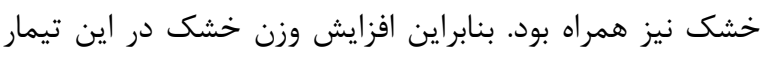
ناشى از افزايش رنكيزه هاى فتوسنتزى با استفاده از نيترات

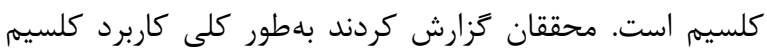

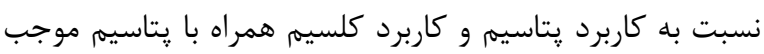
حفظ بهتر فتوسنتز و حفظ پايدارى غشا در شرايط تنش شورى مىشود (Kafi et al., 2013). با وجود اثرات مثبت نيترات

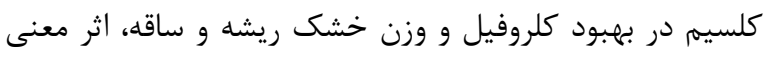

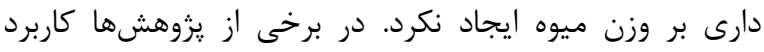

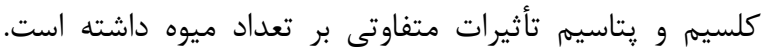

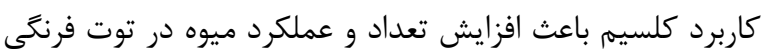

مشخص كرد كه منابع پتاسيمى و كلسيمى در شرايط بدون تنش سبب كاهش وزن خشك اندام هوايى و ريشه شد و تنها

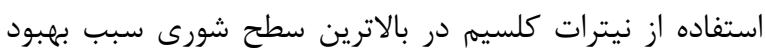

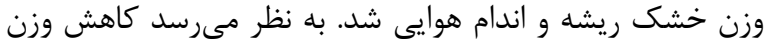
خشك كياه در تيمارهاى تلفيقى يتاسيم و كلسيم مكمل احتمالا

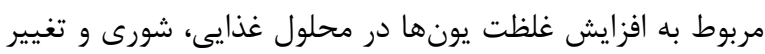
يتانسيل آبى سلولهاى ريشه و اختلال در فرايند انتقال يونها به إنهائ

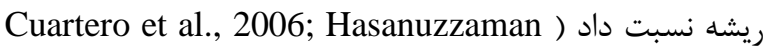
فاز (et al., 2018 در خصوص كودهاى نيتراته برخى از مطالعات افزايش عملكرد با مصرف مقادير اضافى نيتروزن در شرايط شور

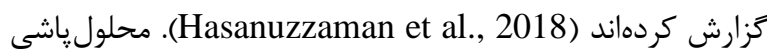

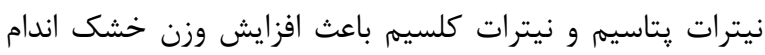
هوايى توتفرنكى شد. در اين مطالعه نيز در بيشترين غلظت كلريد سديم، كاربرد كلريد كلسيم باعث كاهش وزن خدن خشك اند اندام

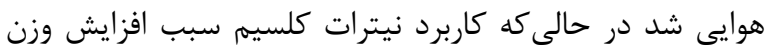

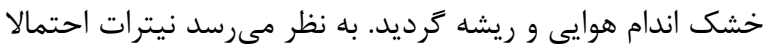

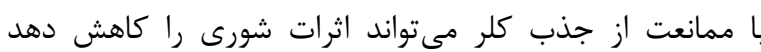
(Akram et al., 2009) نتايج تحقيقات بر كياه آفتابكردان نشان داد استفاده از يتاسيم

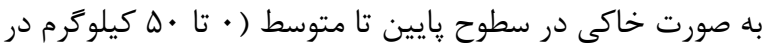

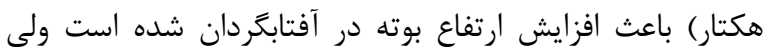

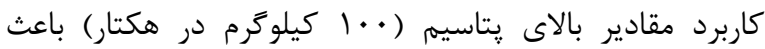
كاهش ارتفاع كياه مى كردد (Mirzapour et al., 2003).

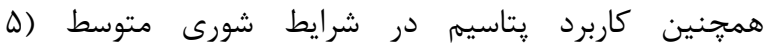

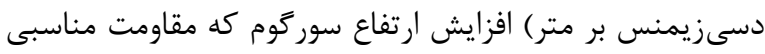

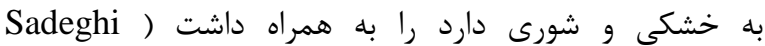

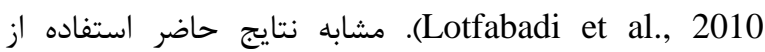
نمكهاى كلريد رتاسيم و كلسيم در كاهش ارتفاع بوتههاى كوجهفرنكى نيز مشاهده شد (Mokhtary et al., 2010) كه احتمالا اثر مثبت اين عناصر بر مقاومت به شئه شورى كياه، تحت

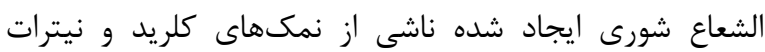
يتاسيم قرار كرفته است. همانند يافتههاى اين تحقيق، كاربرد

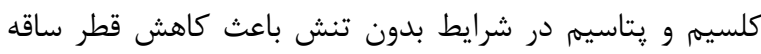
كوجه فرنكى گرديد و همينطور در تيمارهاى شورى بلى كاربرد

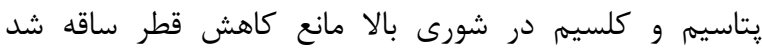
Sadeghi (Fatemi et al., 2010) مشاهده كردند شورى باعث كاهش (Lotfabadi et al., 2010 معنى دار قطر ساقه در سورگوم شده و با كاربرد يتاسيم قطر ساقه

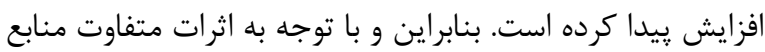
كلسيمى و يتاسيمى و شورى به نظر مىرسد اثرات منابع كلسيم 
ياسخ به تنش شورى با افزايش غلظت سديم اندام هوايى همراه شد (Song \& Fujiyama, 1996) يتاسيم در اين تحقيق نيز مشاهده شد كه به نظر وابسته به سرده، كونه، غلظت شورى و غلظت منابع مورد استفاده است.

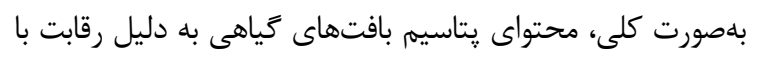

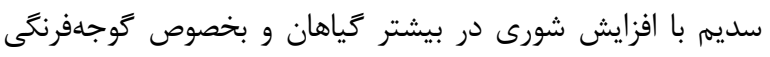

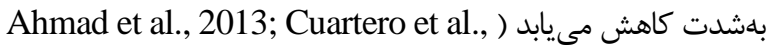
2006). فعاليت آنزيم هاى موجود در سيتويلاسم حساسيت زيادى (. ماند

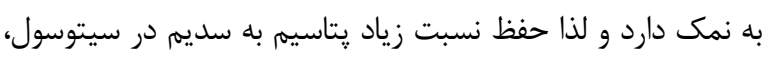

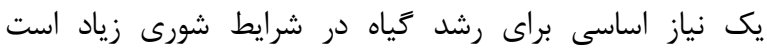

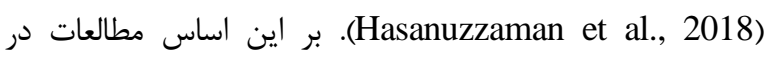
كياهان مختلف و گوجهفرنكى بيانكر اين است كه كاربرد يتاسيم در

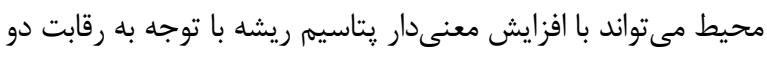

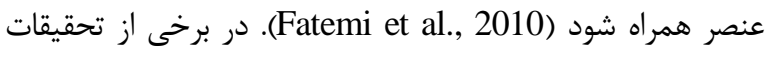
كذشته كاربرد كلسيم در شرايط شورى باعث افزايش يتاسيم درد

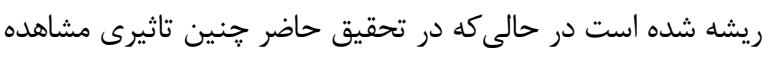

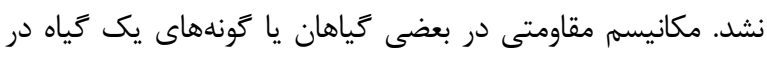

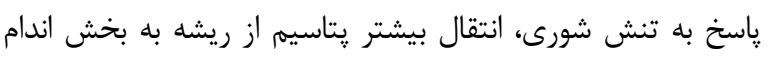

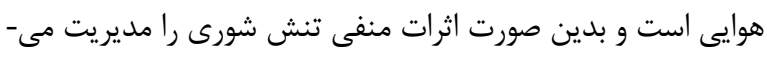

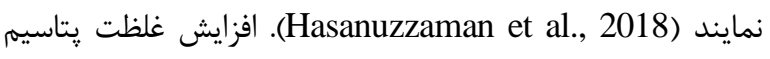

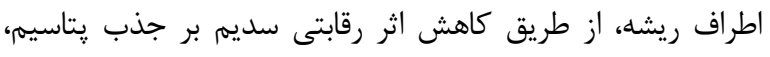

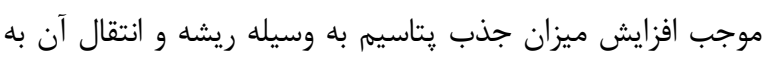

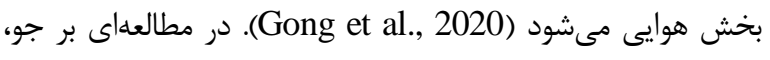

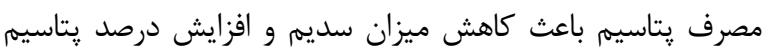

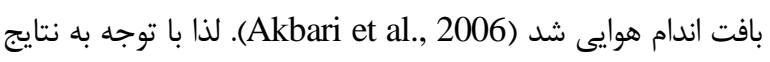

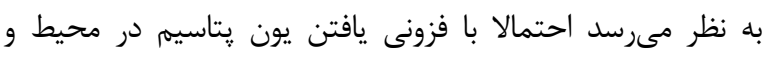

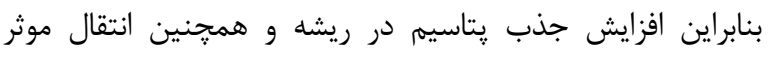

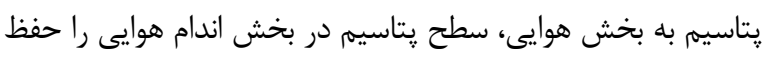

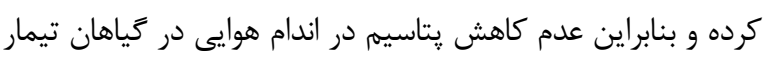
شده با منابع يتاسيمى مى تواند ناشى از ازين اين مكانيسم باشد.

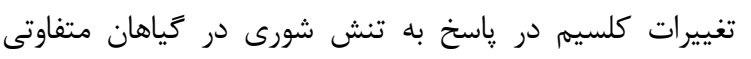

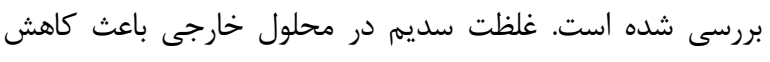

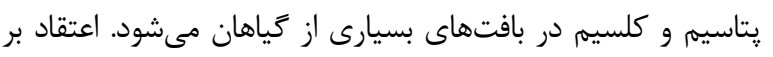

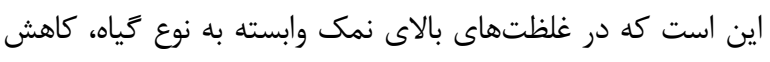

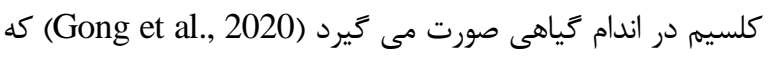

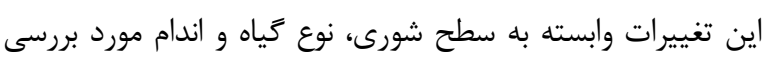

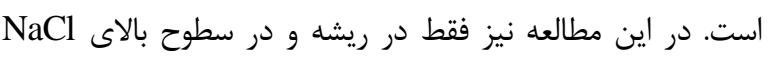

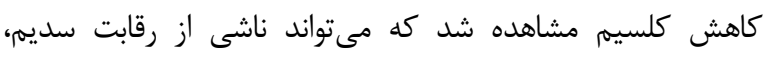

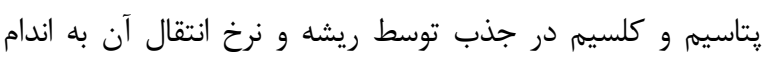
هوايى باشد )
شده است (Khayyat et al., 2007). ولى در تحقيق حاضر تأثير

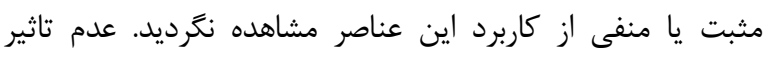

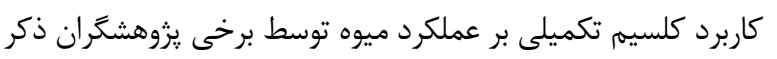

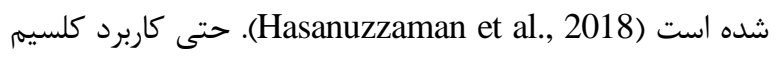
تكميلى بيشترين اثر منفى را بر روى تعداد ميوه توت فرنكى و و

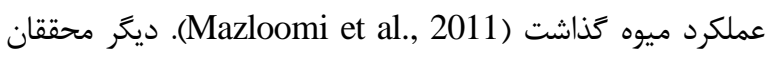
كاهش وزن ميوه توتفرنكى با (Cengiz Kaya et al., 2001) كاربرد كلريد سديم را كزارش كردند و نشان دادند كه كاربرد كلسيم

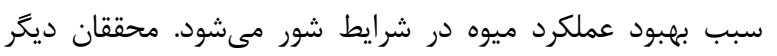

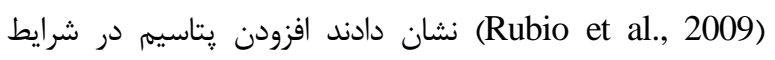
متوسط شورى به محلول غذايى باعث افزايش تعداد ميوه شد كه

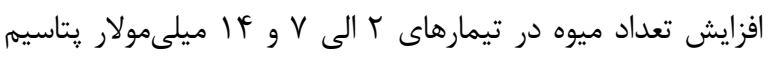

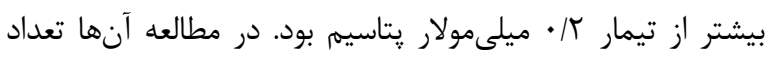
ميوه تحت تاثير كلسيم قرار نداشت.

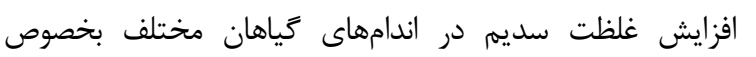

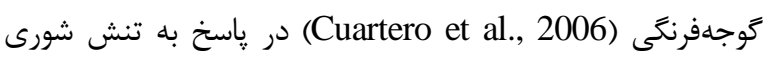

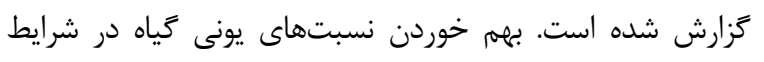

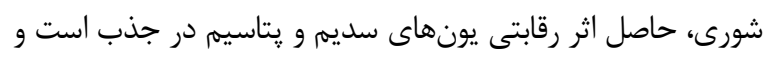
بدين ترتيب سميت سديم فراهم مى خردد (

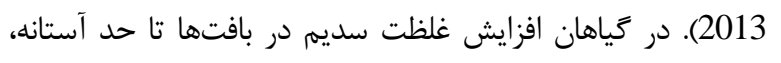

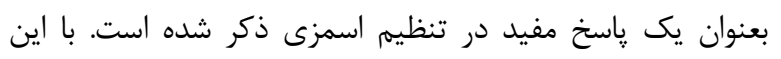

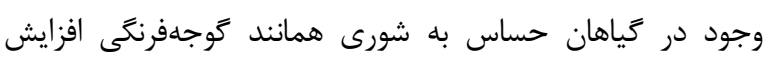

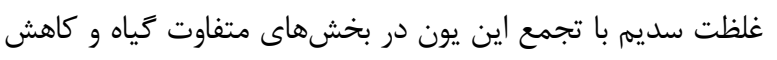

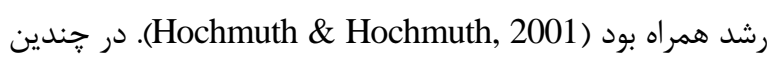
مطالعه، با افزايش پِتاسيم در محيط، غلظت سديم در بخش هوايى

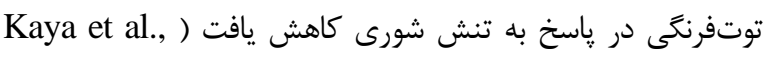

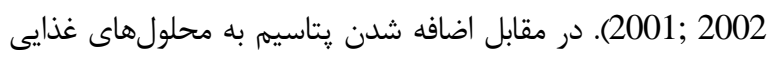
با

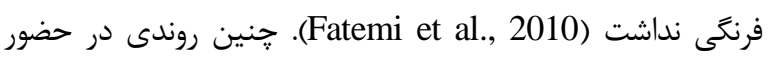
NaCL

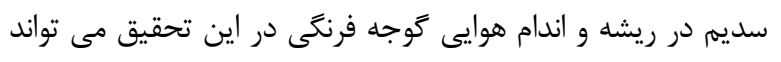

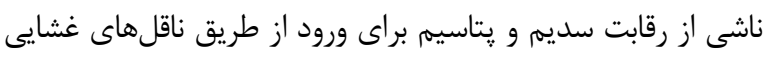

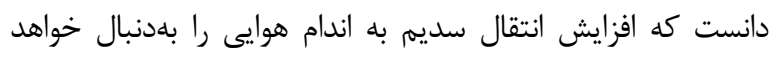
داشت (Ahmad et al., 2013; Cuartero et al., 2006). با توجه انته به اثرات مثبت استفاده از منابع يتاسيم در كياهان مختلف، در مقابل

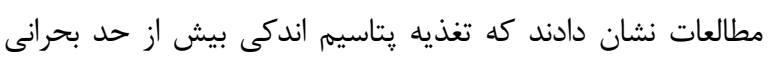

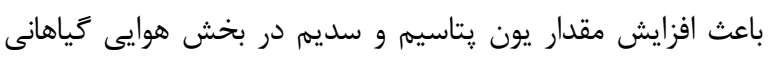

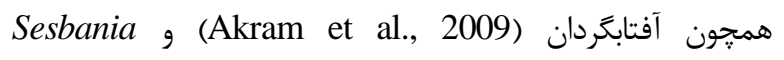
شده و سميت يونها و تشديد

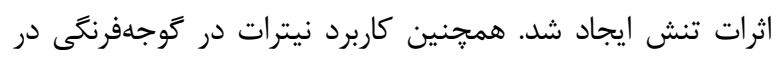




\section{REFERENCES}

Abogadallah, G.M. 2010. Antioxidative defense under salt stress. Plant Signaling and Behavior 5: 369-374.

Ahmad, P., Azooz, M. \& Prasad, M. N. V. 2013. Salt stress in plants: signalling, omics and adaptations: Springer Science \& Business Media, 495 pp.

Akbari, G.A., Foughi, B., Adim, H., Mokhtasi Bid Goli, A., Rahimian Mashhadi, H.R. \& Zand, E. 2006. Investigation of morphophysiological aspects wheat cultivars on their yield augmentation released during past 50 years. Journal of Agricultural Sciences and Natural Resources 13: 58-66

Akram, M.S., Ashraf, M. \& Akram, N.A. 2009. Effectiveness of potassium sulfate in mitigating saltinduced adverse effects on different physiobiochemical attributes in sunflower (Helianthus annuus L.). Flora-Morphology, Distribution, Functional Ecology of Plants 204: 471-483.

Cuartero, J., Bolarin, M., Asins, M. \& Moreno, V. 2006. Increasing salt tolerance in the tomato. Journal of Experimental Botany 57: 1045-1058.

Fatemi, M., Hashemimajd, K., Esmaeili, G. \& Khosgoftarmanesh, A. 2010. The effect of adding potassium, calcium and silicon to the nutrient solution on tomato resistance to salinity in hydroponic culture. (M.Sc. dissertation.), University of Mohaghegh Ardabili, Ardabil, 90 pp.

Forghani, A.H., Almodares, A. \& Ehsanpour, A.A. 2018. Potential objectives for gibberellic acid and paclobutrazol under salt stress in sweet sorghum (Sorghum bicolor [L.] Moench cv. sofra). Applied Biological Chemistry 61: 113-124.

Forghani, A.H., Almodares, A. \& Ehsanpour, A. A. 2020. The role of gibberellic acid and paclobutrazol on oxidative stress responses induced by In vitro salt stress in sweet sorghum. Russian Journal of Plant Physiology 67: 555563.

Ghahremaninejad, F., Hoseini, E. \& Fereidounfar, S. 2021. Cities in drylands as artificial protected areas for plants. Biodiversity and Conservation 30: 243-248.

Gong, Z., Xiong, L., Shi, H., Yang, S., Herrera-Estrella, L.R., Xu, G. \& Qin, F. 2020. Plant abiotic stress response and nutrient use efficiency. Science China Life Sciences 63: 635-674

Gorgi, M., Zahedi, M. \& Khoshgoftarmanesh, A.H. 2010. The effects of potassium and calcium on the response of safflower to salinity in hydroponic nutrient solution. Water and Soil Science 14: 1-7.

Hasanuzzaman, M., Fujita, M., Oku, H., Nahar, K. \& Hawrylak-Nowak, B. 2018. Plant nutrients and abiotic stress tolerance: Springer, Singapore, $590 \mathrm{pp}$.

Heidarpour, S., Abbaspour, N., Mohammadkhani, N. \& Mosavi pornaki, S. 2021. The effect of salt stress on ion accumulation, photosynthesis and compatible solute contents in four grapevine (Vitis vinifera) genotypes. Nova Biologica Reperta 7: 400-410.

Hochmuth, G.J. \& Hochmuth, R.C. 2001. Nutrient solution formulation for hydroponic (perlite, rockwool, NFT) tomatoes in Florida. HS796. Univ. Fla. Coop. Ext. Serv., Gainesville, Pp: 1-10.

Jenkins, J.A. 1948. The origin of the cultivated tomato. Economic Botany 2: 379-392 .
2018). اثرات و قدرت يتاسيم در كاهش كلسيم بافتهاى گياهى

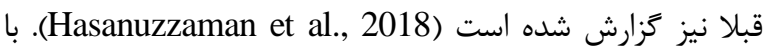
اين وجود نتايج مخالف نيز وجود دارد. كاربرد يتاسيم دره

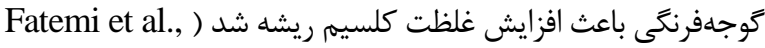

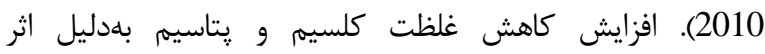
ناهمسازى سديم با يتاسيم يا كلسيم در مكانهاى جذبى ريشه،

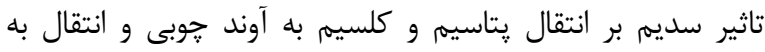
بخش هوايى يا محدود شدن فرايندهاى جذبى است ( Ahmad et al., 2013 ). لذا كاهش درصد كلسيم ريش ريشه در اين مطالعه با وجود

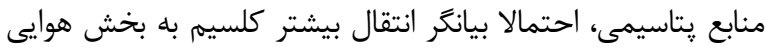

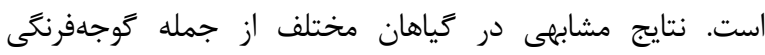
Mazloomi et al., ) و توت فرنغى (Fatemi et al., 2010) 2011) گَزارش شده است. افزايش كلسيم با كاربرد كلسيم نيز سبب Fatemi et al., ) افزايش كلسيم در اندام هوايى گوجهفرنكى شنى 2010). كاربرد كلسيم موجب حفظ پايدارى غشا و كنترل ورود و هو

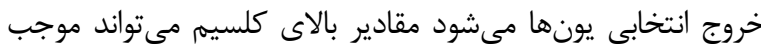
كاهش نفوذ سديم به غشا يلاسمايى شود. كاهش ميزان ورود سديم توسط كلسيم موجب كاهش تجمع سديم از طريق انتقال غير فعال مىشود. غلظت بالاى كلسيم در شرايط شور باعث كاهش انتقال سديم به اندام هوايى مىشود (Hasanuzzaman et al., 2018). بنابراين افزايش غلظت كلسيم با استفاده از منابع خارجى احتمالا اثر رقابتى سديم را تعديل كرده است و افزايش كلسيم در ريشه و اندام هوايى و احتمالا انتقال بيشتر به بخش هوايى رابـ به همراه داشته

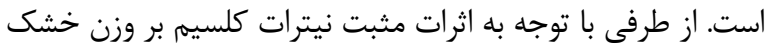

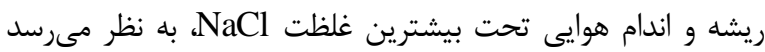
كود نيترات كلسيم در شرايط تنش شورى بهتر از كلريد يتاسيم

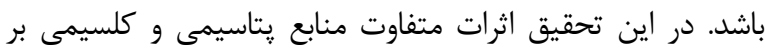
مقاومت به شورى گياه گوجه فرنكى مطالعه شد. با توجه بـ به نتايج،

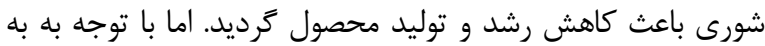

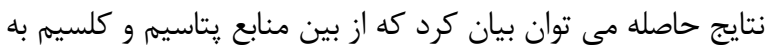

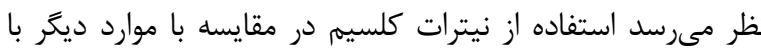
افزايش كلروفيل كل، وزن خشك و تعديل در نسبتهاى يونى

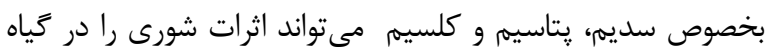
گوجه فرنگى كاهش دهد.

$$
\text { سياسگزارى }
$$

نويسند دانشگاه گيلان و دانشگاه علامه طباطبايى اردبيل كه در انجان اين تحقيق ما را يارى كردند، نهايت قدردانى و تشكر را دارند. 
Jones, J.B. 2001. Laboratory guide for conducting soil tests and plant analysis: CRC press, $384 \mathrm{pp}$.

Kafi, M., Nabati, J., Zare Mehrjerdi, M., Goldani, M., Khaninejad, S., Keshmiri, E. \& Norooziyan, A. 2013. Effect of calcium and potassium on amelioration of negative effects of salinity on some physiological characteristics Kochia (Kochia scoparia). Environmental Stresses in Crop Sciences 5: 181-192.

Karimi, H., Abdolzadeh, A. \& Sadeghipour, H.R. 2008. Effects of potassium nutrition on sesbania aculeate plants grown in greenhouse under salinity. Journal of Agricultural Sciences and Natural Resources 6: 158-170

Kaya, C., Kirnak, H. \& Higgs, D. 2001. Effects of supplementary potassium and phosphorus on physiological development and mineral nutrition of cucumber and pepper cultivars grown at high salinity $(\mathrm{NaCl})$. Journal of Plant Nutrition 24: 1457-1471.

Kaya, C., Kirnak, H., Higgs, D. \& Saltali, K. 2002. Supplementary calcium enhances plant growth and fruit yield in strawberry cultivars grown at high $(\mathrm{NaCl})$ salinity. Scientia Horticulturae 93: 65-74 .

Kaya, C., Tuna, A.L. \& Yokaş, I. 2009. The role of plant hormones in plants under salinity stress. In M. Ashraf, M. Ozturk \& H. R. Athar (Eds.), Salinity and Water Stress: Improving Crop Efficiency. Dordrecht: Springer Netherlands. Pp: 45-50

Khayyat, M., Tafazoli, E., Eshghi, S., Rahemi, M. \& Rajaee, S. 2007. Salinity, supplementary calcium and potassium effects on fruit yield and quality of strawberry (Fragaria ananassa Duch.). American-Eurasian Journal of Agricultural and Environmental Sciences 2: 539-544.

Mazloomi, F., Ronaghi, A. \& Karimian, N. 2011. Influence of salinity and supplementary calcium on vegetative growth, fruit yield and concentration of some nutrients in hydroponically-grown strawberry. Journal of Science and Technology of Greenhouse Culture 2: 51-62

Mirzapour, M.H., Khoshgoftar, A.H., Mirnia, S.K., Bahrami, H.A. \& Naeini, M.R. 2003. Interactive effects of potassium and magnesium on growth and yield of sunflower in a saline soil. Iranian Journal of Soil and Waters Sciences 17: 132-139

Mohammad, M.J., Malkawi, H.I. \& Shibli, R. 2003. Effects of arbuscular mycorrhizal fungi and phosphorus fertilization on growth and nutrient uptake of barley grown on soils with different levels of salts. Journal of Plant Nutrition 26: 125-137.

Mokhtary, I., Abrishamchi, P. \& Ganjali, A. 2010. Ameliorative effects of cacls $_{2}$ and casO $_{4}$ on growth, content of solouble proteins, solouble sugars, proline and some mineral nutrients $\left(\mathrm{Na}^{+}, \mathrm{k}^{+}\right)$in leaves of Lycopersicon esculentom var mobile under salt stress. Iranian Journal of Biology 23: 62-72

Navarro, J.M., Martınez, V. \& Carvajal, M. 2000. Ammonium, bicarbonate and calcium effects on tomato plants grown under saline conditions. Plant Science 157: 89-96.

Nejadhabibvash, F. \& Rezaee, M.B. 2021. The effect of salinity on seed germination, early seedling growth and anatomical structure of Beta vulgaris. Nova Biologica Reperta 7: 419-430.

Rubio, J., Garcia-Sanchez, F., Rubio, F. \& Martinez, V. 2009. Yield, blossom-end rot incidence, and fruit quality in pepper plants under moderate salinity are affected by $\mathrm{K}^{+}$and $\mathrm{Ca}_{2}{ }^{+}$fertilization. Scientia Horticulturae 119: 7987.

Sadeghi Lotfabadi, S., Kafi, M. \& Khazaei, H.R. 2010. Effects of calcium, potassium and method of application on sorghum (sorghum bicolor) morphological and physiological traits in the presence of salinity. Journal of Water and Soil 24: 385-393.

Song, J.Q. \& Fujiyama, H. 1996. Ameliorative effect of potassium on mice and tomato subjected to sodium salinization. Soil Science and Plant Nutrition 42: 493-501.

Zaman, B., Niazi, B., Athar, M. \& Ahmad, M. 2005. Response of wheat plants to sodium and calcium ion interaction under saline environment. International Journal of Environmental Science and Technology 2: 7-12.

How to cite this article:

Forghani, A., Forghani, A.H., Altafi, M., Hashemi Majd, K. \& Sofalian, O. 2021. The effects of different sources of potassium and calcium on yield and ionic balance of tomatoes under salinity stress in hydroponic cultivation. Nova Biologica Reperta 8: 206-219. (In Persian).

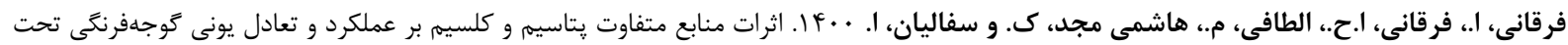

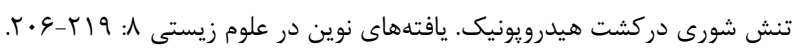

